\title{
Reevaluating the Solution Photophysics of Tetraphenylethylene at the Origin of their Aggregation-Induced Emission Properties
}

\author{
Jean Rouillon*, Cyrille Monnereau* and Chantal Andraud \\ KEYWORDS: Aggregation-induced emission, photophysics, photoisomerization, actinometry
}

ABSTRACT: Although tetraphenylethylene (TPE) and its derivatives have been the most commonly used building blocks in the construction of molecules with Aggregation-Induced Emission (AIE) properties, no absolute consensus exists regarding the mechanisms at the origin of the phenomenon. Restriction of Intramolecular Rotations (RIR) of peripheral phenyls has historically been a dominant paradigm which has served as a valuable guideline in the molecular engineering of AlEgens. Yet, an increasing number of recent works have established that photoisomerization or photocyclization may actively participate in the nonradiative dissipation of the excitation energy. In this paper, we bring the first experimental evaluation of the quantum efficiencies of these different processes, and show that photoisomerization is by far the dominant photophysical pathway in solution, accounting for virtually all nonradiative decay of the molecule's excited state in degassed solution.

The dynamics of molecules at their electronic excited states results from the interplay of a diversity of radiative and nonradiative kinetic processes. ${ }^{1}$ In this framework, the physical state of the molecule, i.e. solution or solid state, plays a particularly determining role. ${ }^{2-4}$ While progresses in the molecular engineering of luminescent compounds in solution has not ceased since the middle of the $19^{\text {th }}$ century, ${ }^{5}$ the design of solid-state fluorophores has experienced a breakthrough in the early 2000s, with the concept of Aggregation-Induced Emission $(\mathrm{AIE})^{6}$ popularized by B.Z. Tang and the burst of new technologies based on solid-state fluorescence. ${ }^{7,8}$

Among the so called AIEgens, tetraphenylethylene (TPE) stands out for its tremendous AIE properties ${ }^{9}$ which are preserved even in highly substituted derivatives. ${ }^{10-12}$ Until very recently, intensification of TPE luminescence in the aggregated state was coined, by analogy with the established AIE mechanism in tetraphenylsiloles, ${ }^{13}$ to the restriction of intramolecular rotations (RIR) of peripheral phenyls : other photophysical processes such as, for instance, double-bond isomerization, were considered to play a negligible role in the AIE properties $^{14}$. The predominance of this model has however recently been put into question by various theoretical studies as well as time-resolved spectroscopy, which suggested the importance of both E/Z photoisomerization (EZI), ${ }^{15-17}$ and photocyclisation (PC), resulting in the formation of diphenylphenanthrene (DPA), ${ }^{18-21}$ as processes in the deexcitation pathways of TPE in solution.

The link between rotation of the central $\mathrm{C}=\mathrm{C}$ bond and fluorescence efficiency in solution $\left(\Phi_{f}\right)$ has been indirectly confirmed by the synthesis and comparative spectroscopic studies of dicyclic cis-TPE and gem-TPE22 (Scheme 1a). In the former, where cyclisation constrains photoisomerization of the double bond, a strong fluorescence is achieved in solution $\left(\Phi_{f}=0.22\right)$; conversely, in the latter, where free rotation of the double bond remains possible, an almost quantitative luminescence quenching is observed $\left(\Phi_{f}=0.019\right)$. Yet, in spite of above-mentioned studies and a growing arrays of evidence that a conical intersection $(\mathrm{Cl})$ is involved in the excited state dynamics of TPE, no absolute consensus exist as to what govern the subsequent evolution of this excited state as illustrated by the most recent publications invoking either the RIR model, ${ }^{23} \mathrm{EZI}^{15}$ or $P C^{18}$ as the major process responsible for the photophysics of TPE derivatives.
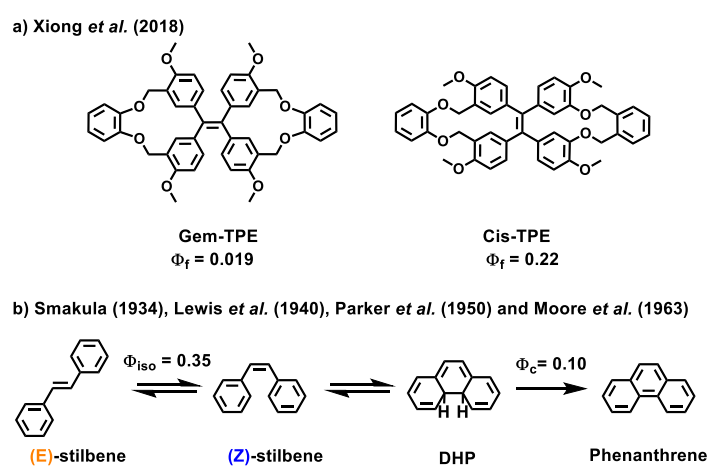

c) Olsen et al. (1979)

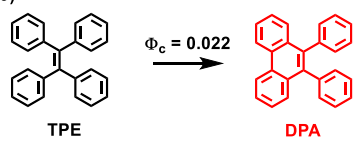

d) This work

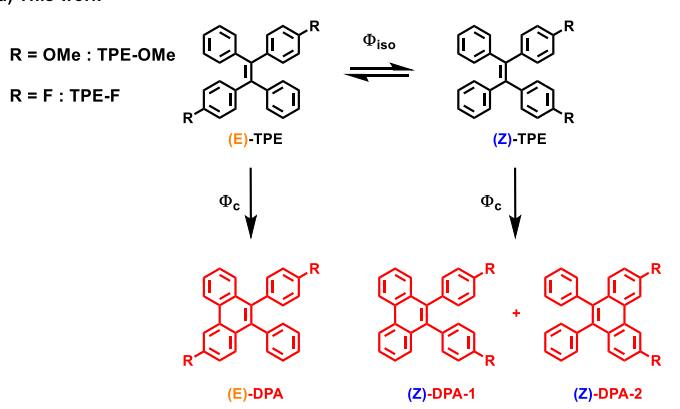

Scheme 1. Experimental quantum yields associated to (a) Fluorescence of TPE dicycles (b) PC of TPE (c) EZI and PC of stilbene, as reported in literature; (d) Photochemical (EZI and PC) mechanisms considered in this article, on TPE derivatives.

Definitive assessment of the weight of these different processes in the photophysics of TPE in solution would only be possible through the determination of their respective quantum yields (QY). The estimation of such QYs has been studied in details for nearly 90 years on stilbene derivatives ${ }^{24-27}$, enabling precise quantification of the photoisomerization process $\left(\Phi_{\text {iso }}\right)^{28-34}$ and photocyclization process to unstable dihydrophenanthrene (DHP), followed by its oxidation to stable phenanthrene $\left(\Phi_{c}\right)$ (Scheme 1b). ${ }^{27,35-41}$ 
a)

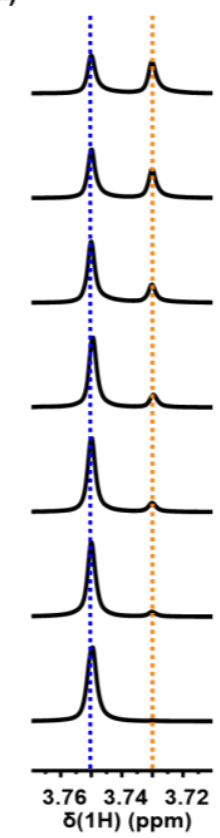

b)

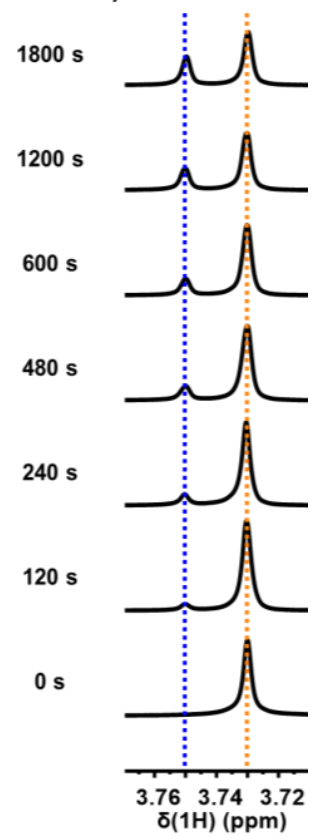

Figure 1. Close-up view on methoxy region of $1 \mathrm{H}$ NMR spectra of (a) (Z)-TPE-OMe and (b) (E)-TPE-OMe during irradiation (in $\mathrm{CDCl} 3$, at room temperature, with a spectrometer operating at $400 \mathrm{MHz}$,

On the other hand, such studies have never been carried out on TPE derivatives: no $\Phi_{\text {iso }}$ determination is reported and only an article indicates a yield $\Phi_{c}=0.022^{42}$ in solution in benzene for the TPE photocyclization (Scheme 1c). Compared to stilbene derivatives, study of the photochemistry of TPE presents major difficulties. Unsubstituted TPE does not present intrinsic $E / Z$ isomerism, and difunctionalization is therefore required to afford a mean to track the process by standard spectroscopic methodologies. ${ }^{15}$ Even so, stereoselective syntheses of TPE derivatives turn out to be complex and examples are scarce, ${ }^{12}$ making it in most cases necessary to separate the as-obtained $\mathrm{E} / \mathrm{Z}$ isomers. These TPE isomers purifications involve tedious processes such as stereoselective recrystallization, ${ }^{43}$ or difficult separations by chromatographic column ${ }^{44}$ or HPLC ${ }^{45}, 46$ which do not always yield stereopure fractions, an essential requisite for the $\Phi_{\text {iso }}$ estimation. In addition, contrary to stilbenes, the UV-vis absorption and emission spectral signature of disubstituted (E/Z)-TPE isomers are generally similar, ${ }^{17}$ precluding their use in the following of photoisomerization processes.

In contrast, even simple TPE derivatives such as the TPEOMe and TPE-F isomers (Scheme $1 \mathrm{~d}$ ) recently described by Kokado et al. show distinct ${ }^{1} \mathrm{H}$ NMR signals for their two diastereisomers. ${ }^{17}$

Therefore, monitoring photoisomerization kinetics by ${ }^{1} \mathrm{NMR}$ should be possible, with a precise determination of the absorbed photon flux. This determination is made possible by performing the irradiation of an NMR tube in integrating sphere, using a chemical actinometer as a reference. ${ }^{47}$

After carrying out the synthesis and separations of (E/Z) TPEOMe isomers (See $\mathrm{SI}$ ), we use the above depicted protocol to study and quantify the photochemical processes in solution.
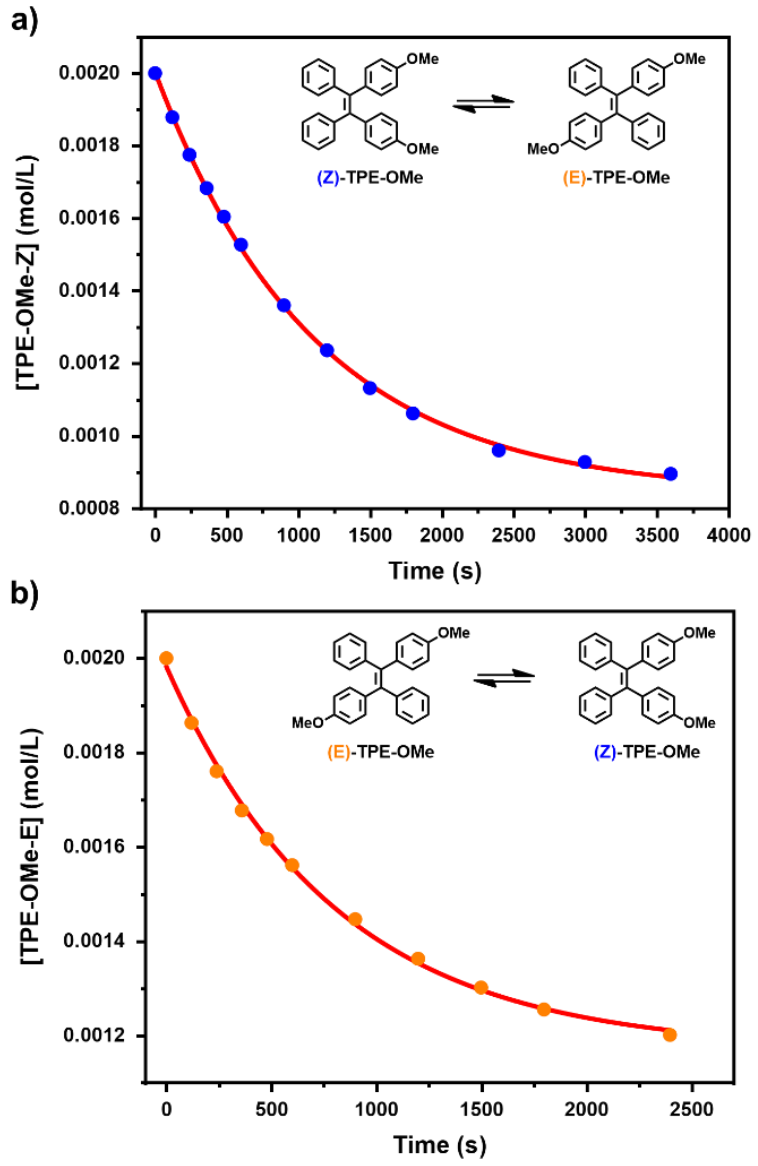

Figure 2. Photoisomerization kinetics of (a) (Z)-TPE-OMe and (b) (E)-TPE-OMe in the absence of oxygen (Red curve corresponding to exponential fit)

A first series of irradiation experiments were carried out on TPE-OME (Z) and (E) isomers in degassed $\mathrm{CDCl}_{3}$ solution (Figures 1 and 2). During the irradiation of pure (Z)-TPE-OMe solution (Figure 1a), the intensity of the methoxy peak associated to the (Z)-isomer at $3.75 \mathrm{ppm}$ (highlighted by the blue dotted line) decreases progressively with a concomitant increase of the intensity of the methoxy peak of the (E)-isomer at 3.73 ppm (highlighted by the yellow dotted line). As expected, the opposite behavior is observed upon irradiation of a pure (E)TPE-OMe isomer solution (Figure 1b). Quite remarkably, in spite of prolonged irradiation times, no other degradation products are detected by NMR in degassed conditions.

The evolution of the relative intensity of each peak result in both cases in similar photoisomerization kinetic profiles (Figure 2). In both cases excellent accuracy is seen when fitting the experimental data to a mono-exponential decay (red curve). The kinetic model associated to the reversible photoinduced interconversion of isomers where both the $\mathrm{Z} \rightarrow \mathrm{E}$ and $\mathrm{E} \rightarrow \mathrm{Z}$ reactions are activated by the same irradiation wavelength is not trivial, as description of the associated equilibria rely on coupled differential equations. However, the kinetic constant of photoisomerization $\mathrm{k}_{\text {iso }}$ can be deduced (or approximated) according to several reported methods. In this work, we chose to 
compare the values obtained using two distinct methods, in order to ensure the reliability of the data (i) an exact method treatment developed by Bayda et al. ${ }^{48}$ and (ii) the empirical method of extrapolation to zero-time. ${ }^{49}$ Both methods and associated calculations are briefly described in the SI.

From those $k_{\text {iso. }}$ values, photoisomerization quantum yield could be readily deduced using Equation 1:

$$
\Phi_{\text {iso }}=\frac{\text { isu } \mathrm{n}}{I \text {. }}
$$

where $\mathrm{k}_{\text {iso }}$ is the kinetic constant of the considered photoinduced process (here, the isomerization) (mol. $\mathrm{L}^{-1} . \mathrm{s}^{-1}$ ), $\mathrm{N}_{\mathrm{A}}$, the Avogadro constant, $\mathrm{V}$, the volume of the solution ( $\mathrm{L}$ ), and $\mathrm{l}_{\mathrm{abs}}$, the absorbed photon flux $\left(\mathrm{s}^{-1}\right)$. Calculations are presented as Supporting Information (SI part 2).

In order to confirm the validity of the proposed approach, determination of the photoisomerization quantum yield of a stilbene derivative (difluorostilbene, Figure S11) was first undertaken. An isomerization quantum yield $\Phi_{\text {iso }}=0.39$ was found for the (E)-stilbene derivative S-F (Figure S11), in good agreement with previously published data on related systems(Scheme 1b)..$^{34}$ This brings conclusive support to the reliability and robustness of the protocol, which led us to extend it to the study of TPE derivatives.

For TPE-OMe, photoisomerization QYs obtained for its (Z) and $(E)$ isomer were similar within an acceptable ca $5 \%$ error margin: $\Phi_{\text {iso }}=0.53$ for the $(Z)$-isomer and $\Phi_{\text {iso }}=0.50$ for the $(E)$ isomer (Table 1).

These values clearly indicate that, in degassed media, photoisomerization is the major and probably exclusive process taking place at their excited state, thus accounting for quasiquantitative quenching of the luminescence. This conclusion is consistent with the predictions from recent theoretical studies which stated that nonradiative decay to the fundamental states of either the $(Z)$ or the $(E)$ isomer through a conical intersection $(\mathrm{Cl})$ seems equiprobable (quasi-symmetry of the potential energy surfaces on both sides of the $\mathrm{Cl}$ ). ${ }^{17,50,51}$ As a consequence of the spectroscopic approach used in our protocol, only $Z \rightarrow E$ and $E \rightarrow Z$ can be observed while $Z \rightarrow Z$ and $E \rightarrow E$ transitions are spectroscopically "silent". Accordingly, quantum efficiency associated to all processes related to rotations around the central double bond, $\Phi_{\text {rot }}$ can be approximated by $\Phi_{\text {rot }}=2 \Phi_{\text {iso, }}{ }^{52,53}$ which, in the present case translates into $\Phi_{\text {rot }} \sim 1$. In other words, virtually all photons absorbed by TPEOMe result in a rotation of the molecule around its central double bond, which constitute the first direct experimental evidence that, following access of the $\mathrm{Cl}$, photoisomerization plays a pivotal role in the photophysics of TPE derivatives in solution.

Table 1. EZI and PC QYs of TPE-OMe isomers in degassed and undegassed solutions.

\begin{tabular}{ccccc}
\hline & \multicolumn{2}{c}{$(\mathbf{Z})$-TPE-OMe } & \multicolumn{2}{c}{$(\mathbf{E})$-TPE-OMe } \\
\hline & Degassed & Undegassed & Degassed & Undegassed \\
$\Phi_{\text {iso }}$ & 0.53 & 0.51 & 0.50 & 0.48 \\
$\Phi_{\mathrm{C}}$ & n.c. & 0.05 & n.c. & 0.05 \\
\hline
\end{tabular}

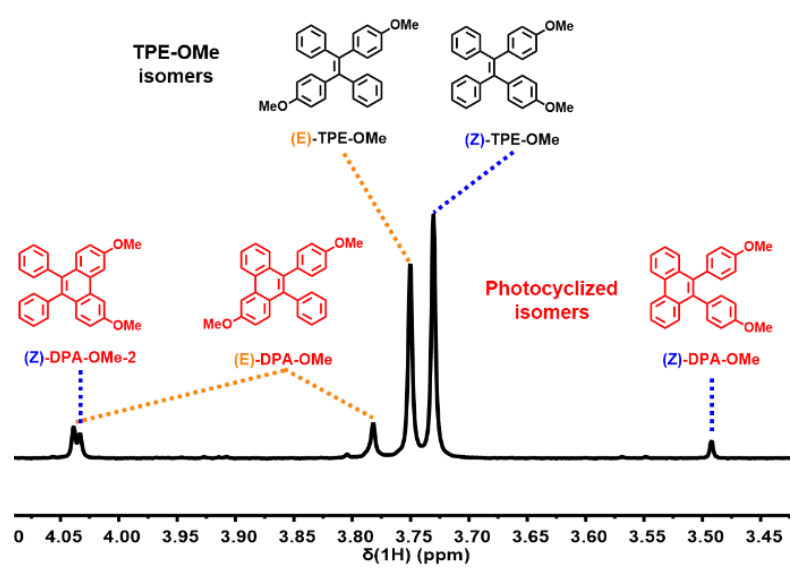

Figure 3. Close-up view on methoxy region of ${ }^{1} \mathrm{H}$ NMR spectrum after $3600 \mathrm{~s}$ irradiation of (E)-TPE-OMe solution in $\mathrm{CDCl}_{3}$. Assignments of TPE-OMe isomers and photocyclized DPA-OMe isomers are made.

In non-degassed solution, in addition to the characteristic evolution in the ${ }^{1} \mathrm{H}$ NMR spectrum resulting from isomerization, as depicted above, irradiation of stereopur TPE-OMe, (Z) or $(E)$, led to the appearance of a new set of methoxy peaks, which could be unambiguously attributed to different isomers of photocyclized DPA-OMe (Figure 3). As mentioned in the introduction, the presence of oxygen constitutes a driving force in the build-up of PC compounds, which evolve from unstable photo-cyclized intermediates through a final oxidation step, by analogy with well-known stilbene derivatives (Figure 1b). In order to refine our understanding of the photochemistry of TPE derivatives in oxygenated media, we attempted to evaluate the $\Phi_{\mathrm{c}}$ values of TPE-OMe isomers in parallel to its $\Phi_{\text {iso }}$ (Table 1 and detailed procedure in $\mathrm{SI}$ ).

For both (E) and (Z)-TPE-OMe, the initial decrease in the total concentration of uncyclized derivatives (alt. increase in the concentration of cyclized derivatives) follows a pseudo-order 0 kinetic for this irreversible slow reaction in its initial stage (Figure 4) from which the PC kinetic constant $k_{c}$ can be calculated by linear fitting. This constant can be used to calculate, for each isomer, a photocyclisation quantum yield $\Phi_{c}=0.05$ (Table 1 and Figure S6). Note that taking this process into account

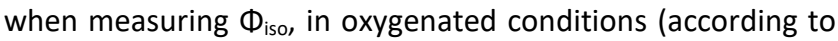
equations S7-9) results in only a slight lowering of the value compared to degassed solution ( 0.51 and 0.48 , for the $\mathrm{Z}$ and $\mathrm{E}$ isomers respectively).

These $\Phi_{c}$ are in good agreement with those recently measured by Olsen et al., using a different approach on a variety of unsubstituted and substituted TPE derivatives. ${ }^{42} \mathrm{As}$ a confirmation, we performed a similar experiment on the unsubstituted TPE, also studied by Olsen, and found a very similar quantum yield $\Phi_{c}=0.05$, suggesting that methoxy substitution do not strongly affect the photophysics of the molecule. All these results constitute additional evidences that, in contrast with recent TD-DFT predictions, ${ }^{18}$ PC processes do not seem to play a significant role in the photophysics of TPEs : in both deaerated and oxygenated conditions, photoisomerization is the dominant nonradiative process in solution (i.e., $2 \Phi_{\text {iso }} \sim 1$ ). 


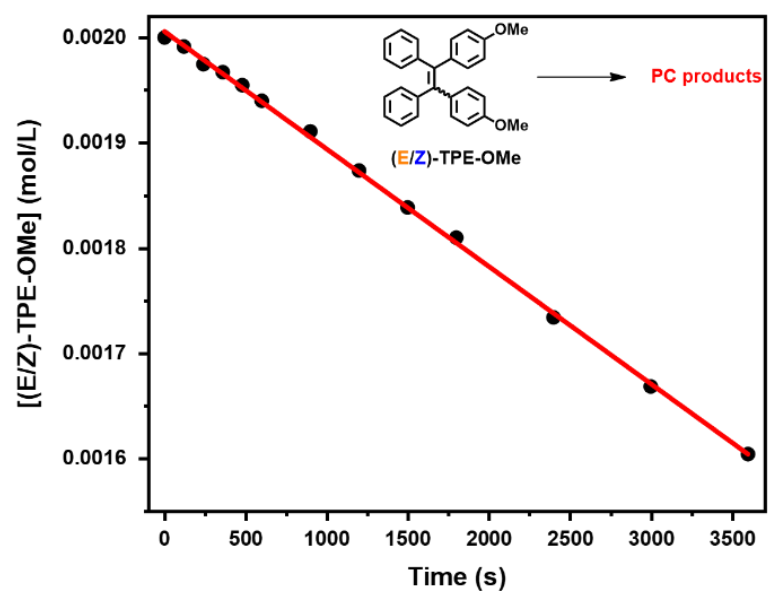

Figure 4. Photocyclization kinetic of (Z)-TPE-OMe in undegassed $\mathrm{CDCl}_{3}$ solution (Red line corresponding to the linear fit).

In order to expand our approach, Фiso and Фc were also determined for TPE-F isomers in undegassed solution, this time monitoring evolution of their ${ }^{19} \mathrm{~F}$ NMR spectra (Figures S8, S9 and S10). The as-determined yields are summarized in Table 2 ; values and general conclusions of this series of measurements with TPE-F are the same as with TPE-OMe: (i) Фiso 0.50 with $\Phi_{\text {iso }}(Z)$ found slightly higher than $\Phi_{\text {iso }}(E)$ (ii) $\Phi_{c}$ plays only a minor role $(=0.05)$.

Table 2. EZI and PC QYs of TPE-F isomers in undegassed solutions

\begin{tabular}{ccc}
\hline & TPE-F-Z & TPE-F-E \\
\hline$\Phi_{\text {iso }}$ & 0.51 & 0.49 \\
$\Phi_{\mathrm{C}}$ & 0.05 & 0.07 \\
\hline
\end{tabular}

As a short summary, this series of experiments constitute the first direct experimental confirmation and quantification of the determining (and quasi exclusive) influence of photoisomerization processes on the photophysics of TPE based AIEgens.

\section{ASSOCIATED CONTENT}

Experimental procedures and kinetic treatments of the photoconversion curves are provided as $\mathrm{SI}$

\section{AUTHOR INFORMATION}

\section{Corresponding Author}

* Jean Rouillon - Laboratoire de Chimie, Univ. Lyon, ENS Lyon, CNRS, Université Lyon 1, 69364

Email: jean.rouillon@laposte.net

* Cyrille Monnereau - Laboratoire de Chimie, Univ. Lyon, ENS Lyon, CNRS, Université Lyon 1, 69364 Lyon, France; orcid.org/0000-0002-8928-2416;

Email: cyrille.monnereau@ens-lyon.fr

\section{Author}

Chantal Andraud - Laboratoire de Chimie, Univ. Lyon, ENS Lyon, CNRS, Université Lyon 1, 69364 Lyon, France; orcid.org/0000-0002-4623-3227;

\section{ACKNOWLEDGMENTS}

All the authors would like to thank Mirabelle Menahem for the conception of the graphical table-of-contents.

\section{REFERENCES}

(1) Kim, E.; Park, S. B. Chemistry as a Prism: A Review of Light-Emitting Materials Having Tunable Emission Wavelengths. Chem. - Asian J. 2009, 4 (11), 16461658. https://doi.org/https://doi.org/10.1002/asia.200900102.

(2) Chen, Z.; Lohr, A.; Saha-Möller, C. R.; Würthner, F. Self-Assembled $\pi$ Stacks of Functional Dyes in Solution: Structural and Thermodynamic Features. Chem Soc. Rev. 2009, 38 (2), 564-584. https://doi.org/10.1039/B809359H.

(3) Shi, J.; Aguilar Suarez, L. E.; Yoon, S.-J.; Varghese, S.; Serpa, C.; Park, S. Y.; Lüer, L.; Roca-Sanjuán, D.; Milián-Medina, B.; Gierschner, J. Solid State Luminescence Enhancement in $\pi$-Conjugated Materials: Unraveling the Mechanism beyond the Framework of AIE/AIEE. J. Phys. Chem. C 2017, 121 (41), 23166-23183. https://doi.org/10.1021/acs.jpcc.7b08060.

(4) Würthner, F. Aggregation-Induced Emission (AIE): A Historical Perspective. Angew. Chem. Int. Ed. 2020, 59 (34), 14192-14196 https://doi.org/10.1002/anie.202007525.

(5) Valeur, B.; Berberan-Santos, M. N. A Brief History of Fluorescence and Phosphorescence before the Emergence of Quantum Theory. J. Chem. Educ. 2011, 88 (6), 731-738. https://doi.org/10.1021/ed100182h.

(6) Luo, J.; Xie, Z.; Lam, J. W. Y.; Cheng, L.; Chen, H.; Qiu, C.; Kwok, H. S.; Zhan, X.; Liu, Y.; Zhu, D.; Tang, B. Z. Aggregation-Induced Emission of 1-Methyl1,2,3,4,5-Pentaphenylsilole. Chem. Commun. 2001, No. 18, 1740-1741. https://doi.org/10.1039/B105159H.

(7) Hong, Y.; Lam, J. W. Y.; Tang, B. Z. Aggregation-Induced Emission. Chem Soc. Rev. 2011, 40 (11), 5361-5388. https://doi.org/10.1039/C1CS15113D.

(8) Mei, J.; Hong, Y.; Lam, J. W. Y.; Qin, A.; Tang, Y.; Tang, B. Z. AggregationInduced Emission: The Whole Is More Brilliant than the Parts. Adv. Mater. 2014, 26 (31), 5429-5479. https://doi.org/https://doi.org/10.1002/adma.201401356.

(9) Dong, Y.; Lam, J. W. Y.; Qin, A.; Liu, J.; Li, Z.; Tang, B. Z.; Sun, J.; Kwok, H. S. Aggregation-Induced Emissions of Tetraphenylethene Derivatives and Their Utilities as Chemical Vapor Sensors and in Organic Light-Emitting Diodes. Appl. Phys. Lett. 2007, 91 (1), 011111. https://doi.org/10.1063/1.2753723.

(10) Zhao, Z.; Lam, J. W. Y.; Tang, B. Z. Tetraphenylethene: A Versatile AIE Building Block for the Construction of Efficient Luminescent Materials for Organic Light-Emitting Diodes. J. Mater. Chem. 2012, 22 (45), 23726-23740. https://doi.org/10.1039/C2JM31949G.

(11) La, D. D.; Bhosale, S. V.; Jones, L. A.; Bhosale, S. V. TetraphenylethyleneBased AIE-Active Probes for Sensing Applications. ACS Appl. Mater. Interfaces 2018, 10 (15), 12189-12216. https://doi.org/10.1021/acsami.7b12320.

(12) Yang, Z.; Chi, Z.; Mao, Z.; Zhang, Y.; Liu, S.; Zhao, J.; P. Aldred, M.; Chi, Z. Recent Advances in Mechano-Responsive Luminescence of Tetraphenylethylene Derivatives with Aggregation-Induced Emission Properties. Mater. Chem. Front. 2018, (5), 861-890. https://doi.org/10.1039/C8QM00062J.

(13) Zhao, Z.; He, B.; Tang, B. Z. Aggregation-Induced Emission of Siloles. Chem. Sci. 2015, 6 (10), 5347-5365. https://doi.org/10.1039/C5SC01946J.

(14) Zhao, Z.; Lu, P.; Y. Lam, J. W.; Wang, Z.; K. Chan, C. Y.; Y. Sung, H. H.; D. Williams, I.; Ma, Y.; Zhong Tang, B. Molecular Anchors in the Solid State: Restriction of Intramolecular Rotation Boosts Emission Efficiency of Luminogen Aggregates to Unity. Chem. Sci. 2011, 2 (4), 672-675. https://doi.org/10.1039/COSC00521E.

(15) Kokado, K.; Sada, K. Consideration of Molecular Structure in the Excited State to Design New Luminogens with Aggregation-Induced Emission. Angew. Chem 2019, 131 (26), 8724-8731. https://doi.org/https://doi.org/10.1002/ange.201814462.

(16) Cai, Y.; Du, L.; Samedov, K.; Gu, X.; Qi, F.; Y. Sung, H. H.; O. Patrick, B.; Yan, Z.; Jiang, X.; Zhang, H.; Y. Lam, J. W.; D. Williams, I.; Phillips, D. L.; Qin, A.; Zhong Tang, B. Deciphering the Working Mechanism of Aggregation-Induced Emission of Tetraphenylethylene Derivatives by Ultrafast Spectroscopy. Chem. Sci. 2018, 9 (20), 4662-4670. https://doi.org/10.1039/C8SC01170B.

(17) Kokado, K.; Machida, T.; Iwasa, T.; Taketsugu, T.; Sada, K. Twist of C=C Bond Plays a Crucial Role in the Quenching of AIE-Active Tetraphenylethene Derivatives in Solution. J. Phys. Chem. C 2018, 122 (1), 245-251. https://doi.org/10.1021/acs.jpcc.7b11248.

(18) Guan, J.; Wei, R.; Prlj, A.; Peng, J.; Lin, K.-H.; Liu, J.; Han, H.; Corminboeuf, C.; Zhao, D.; Yu, Z.; Zheng, J. Direct Observation of Aggregation-Induced Emission Mechanism. Angew. Chem. Int. Ed. 2020, 59 (35), 14903-14909. https://doi.org/https://doi.org/10.1002/anie.202004318. 
(19) Gao, Y.-J.; Chang, X.-P.; Liu, X.-Y.; Li, Q.-S.; Cui, G.; Thiel, W. Excited-State Decay Paths in Tetraphenylethene Derivatives. J. Phys. Chem. A 2017, 121 (13), 25722579. https://doi.org/10.1021/acs.jpca.7b00197.

(20) Prlj, A.; Došlić, N.; Corminboeuf, C. How Does Tetraphenylethylene Relax from Its Excited States? Phys. Chem. Chem. Phys. 2016, 18 (17), 11606-11609. https://doi.org/10.1039/C5CP04546K.

(21) Tran, T.; Prlj, A.; Lin, K.-H.; Hollas, D.; Corminboeuf, C. Mechanisms of Fluorescence Quenching in Prototypical Aggregation-Induced Emission Systems: Excited State Dynamics with TD-DFTB. Phys. Chem. Chem. Phys. 2019, 21 (18), 90269035. https://doi.org/10.1039/C9CP00691E.

(22) Xiong, J.-B.; Yuan, Y.-X.; Wang, L.; Sun, J.-P.; Qiao, W.-G.; Zhang, H.-C.; Duan, M.; Han, H.; Zhang, S.; Zheng, Y.-S. Evidence for Aggregation-Induced Emission from Free Rotation Restriction of Double Bond at Excited State. Org. Lett. 2018, 20 (2), 373-376. https://doi.org/10.1021/acs.orglett.7b03662.

(23) Li, W.; Ding, Y.; Tebyetekerwa, M.; Xie, Y.; Wang, L.; Li, H.; Hu, R.; Wang, Z.; Qin, A.; Zhong Tang, B. Fluorescent Aggregation-Induced Emission (AIE)-Based Thermosetting Electrospun Nanofibers: Fabrication, Properties and Applications. $\mathrm{Ma}$ ter. Chem. Front. 2019, 3 (11), 2491-2498. https://doi.org/10.1039/C9QM00342H.

(24) Smakula, A. Über Die Photochemische Umwandlung Des Trans-Stilbens. Z. Für Phys. Chem. 1934, 25B (1), 90-98. https://doi.org/10.1515/zpch-1934-2508.

(25) Lewis, G. N.; Magel, T. T.; Lipkin, D. The Absorption and Re-Emission of Light by Cis-and Trans-Stilbenes and the Efficiency of Their Photochemical Isomerization. J. Am. Chem. Soc. 1940, 62 (11), 2973-2980.

(26) Parker, C. O.; Spoerri, P. E. Photochemical Conversion of Stilbene to Phenanthrene. Nature 1950, 166 (4223), 603-603.

(27) Moore, W. M.; Morgan, D. D.; Stermitz, F. R. The Photochemical Conversion of Stilbene to Phenanthrene. The Nature of the Intermediate. J. Am. Chem. Soc 1963, 85 (6), 829-830.

(28) Schulte-Frohlinde, D.; Blume, H.; Güsten, H. Photochemical Cis-TransIsomerization of Substituted Stilbenes. J. Phys. Chem. 1962, 66 (12), 2486-2491.

(29) Waldeck, D. H. Photoisomerization Dynamics of Stilbenes. Chem. Rev. 1991, 91 (3), 415-436.

(30) Hammond, H. A.; DeMeyer, D. E.; Williams, J. L. Quantum Yields for the Sensitized Photoisomerization of Cis-and Trans-Stilbene. J. Am. Chem. Soc. 1969, 91 (18), 5180-5181.

(31) Muszkat, K. A.; Gegiou, D.; Fischer, E. Temperature Dependence of Photoisomerization. IV. Evidence for the Involvement of Triplet States in the Direct Photoisomerization of Stilbenes. J. Am. Chem. Soc. 1967, 89 (18), 4814-4815.

(32) Saltiel, J.; Marinari, A.; Chang, D. W.; Mitchener, J. C.; Megarity, E. D. Trans-Cis Photoisomerization of the Stilbenes and a Reexamination of the Positiona Dependence of the Heavy-Atom Effect. J. Am. Chem. Soc. 1979, 101 (11), 2982-2996.

(33) Saltiel, J.; Zafiriou, O. C.; Megarity, E. D.; Lamola, A. A. Tests of the Singlet Mechanism for Cis-Trans Photoisomerization of the Stilbenes. J. Am. Chem. Soc. 1968, 90 (17), 4759-4760.

(34) Goerner, H. +; Schulte-Frohlinde, D. Trans. Fwdarw. Cis Photoisomerization of Stilbene and 4-Halogenated Stilbenes, Evidence for an Upper Excited Triplet Pathway. J. Phys. Chem. 1979, 83 (24), 3107-3118.

(35) Mallory, F. B.; Wood, C. S.; Gordon, J. T. Photochemistry of Stilbenes. III. Some Aspects of the Mechanism of Photocyclization to Phenanthrenes. J. Am. Chem Soc. 1964, 86 (15), 3094-3102.

(36) Bromberg, A.; Muszkat, K. A.; Fischer, E. Photocyclisation and Photocyclodehydrogenation of Stilbene and Related Compounds. Isr. J. Chem. 1972, 10 (4) 765-773. https://doi.org/https://doi.org/10.1002/ijch.197200077.

(37) Mallory, F. B.; Mallory, C. W. Photocyclization of Stilbenes and Related Molecules. In Organic Reactions; American Cancer Society, 2005; pp 1-456. https://doi.org/10.1002/0471264180.or030.01.

(38) Blackburn, E. V.; Timmons, C. J. The Photocyclisation of Stilbene Analogues. Q. Rev. Chem. Soc. 1969, 23 (4), 482-503. https://doi.org/10.1039/QR9692300482.

(39) Mallory, F. B.; Gordon, J. T.; Wood, C. S. Photochemistry of Stilbenes. II. Substituent Effects on the Rates of Phenanthrene Formation. J. Am. Chem. Soc. 1963, $85(6), 828-829$

(40) Muszkat, K. A.; Fischer, E. Structure, Spectra, Photochemistry, and Thermal Reactions of the 4a,4b-Dihydrophenanthrenes. J. Chem. Soc. B Phys. Org. 1967 No. 0, 662-678. https://doi.org/10.1039/J29670000662.

(41) Rodier, J. M.; Myers, A. B. Cis-Stilbene Photochemistry: Solvent Dependence of the Initial Dynamics and Quantum Yields. J. Am. Chem. Soc. 1993, 115 (23), 10791-10795. https://doi.org/10.1021/ja00076a041.

(42) Olsen, R. J.; Buckles, R. E. Substituent Effects on the Efficiency and Regioselectivity of Tetraarylethylene Photocyclization. J. Photochem. 1979, 10 (3), 215220. https://doi.org/10.1016/0047-2670(79)80009-X.

(43) Hu, R.; Lam, J. W. Y.; Liu, J.; Sung, H. H. Y.; Williams, I. D.; Yue, Z.; Wong, K. S.; Yuen, M. M. F.; Tang, B. Z. Hyperbranched Conjugated Poly(Tetraphenylethene): Synthesis, Aggregation-Induced Emission, Fluorescent Photopatterning, Optical Limiting and Explosive Detection. Polym. Chem. 2012, 3 (6), 1481-1489. https://doi.org/10.1039/C2PY20057K.

(44) Fang, X.; Zhang, Y.-M.; Chang, K.; Liu, Z.; Su, X.; Chen, H.; Zhang, S. X.-A Liu, Y.; Wu, C. Facile Synthesis, Macroscopic Separation, E/Z Isomerization, and Distinct AIE Properties of Pure Stereoisomers of an Oxetane-Substituted Tetraphenylethene Luminogen. Chem. Mater. 2016, 28 (18), 6628-6636. https://doi.org/10.1021/acs.chemmater.6b02746.
(45) Zhang, C.-J.; Feng, G.; Xu, S.; Zhu, Z.; Lu, X.; Wu, J.; Liu, B. Structure-Dependent Cis/Trans Isomerization of Tetraphenylethene Derivatives: Consequences for Aggregation-Induced Emission. Angew. Chem. 2016, 128 (21), 6300-6304. https://doi.org/10.1002/ange.201600244.

(46) Rouillon, J.; Blahut, J.; Jean, M.; Albalat, M.; Vanthuyne, N.; Lesage, A.; Ali, L. M. A.; Hadj-Kaddour, K.; Onofre, M.; Gary-Bobo, M.; Micouin, G.; Banyasz, A.; Le Bahers, T.; Andraud, C.; Monnereau, C. Two-Photon Absorbing AlEgens: Influence of Stereoconfiguration on Their Crystallinity and Spectroscopic Properties and Applications in Bioimaging. ACS Appl. Mater. Interfaces 2020, 12 (49), 55157-55168. https://doi.org/10.1021/acsami.0c15810.

(47) Rouillon, J.; Arnoux, C.; Monnereau, C. Determination of Photoinduced Radical Generation Quantum Efficiencies by Combining Chemical Actinometry and $19 \mathrm{~F}$ NMR Spectroscopy. Anal. Chem. 2021, 93 (5), 2926-2932. https://doi.org/10.1021/acs.analchem.0c04540.

(48) Bayda, M.; Hug, G. L.; Lukaszewicz, J.; Majchrzak, M.; Marciniec, B.; Marciniak, B. Kinetics of Reversible Photoisomerization: Determination of the Primary Quantum Yields for the E-Z Photoisomerization of Silylenephenylenevinylene Derivatives. Photochem. Photobiol. Sci. 2009, 8 (12), 1667-1675. https://doi.org/10.1039/B907242J.

(49) Zimmerman, G.; Chow, L.-Y.; Paik, U.-J. The Photochemical Isomerization of Azobenzene1. J. Am. Chem. Soc. 1958, 80 (14), 3528-3531.

(50) Crespo-Otero, R.; Li, Q.; Blancafort, L. Exploring Potential Energy Surfaces for Aggregation-Induced Emission-From Solution to Crystal. Chem. - Asian J. 2019, 14 (6), 700-714. https://doi.org/https://doi.org/10.1002/asia.201801649.

(51) Suzuki, S.; Sasaki, S.; Sairi, A. S.; Iwai, R.; Tang, B. Z.; Konishi, G. Principles of Aggregation-Induced Emission: Design of Deactivation Pathways for Advanced AlEgens and Applications. Angew. Chem. Int. Ed. 2020, 59 (25), 9856-9867. https://doi.org/https://doi.org/10.1002/anie.202000940.

(52) Huang, G.-J.; Yang, J.-S. The N-Arylamino Conjugation Effect in the Photochemistry of Fluorescent Protein Chromophores and Aminostilbenes. Chem. $\begin{array}{lllll}\text { Asian J. 2010, } & 5 & \text { (9), 2075-2085. }\end{array}$ https://doi.org/https://doi.org/10.1002/asia.201000209.

(53) Lin, C.-J.; Liu, Y.-H.; Peng, S.-M.; Yang, J.-S. Photoluminescence and Trans $\rightarrow$ Cis Photoisomerization of Aminostyrene-Conjugated Phenylpyridine $\mathrm{C}^{\wedge} \mathrm{N}$ Ligands and Their Complexes with Platinum(II): The Styryl Position and the Amino Substituent Effects. J. Phys. Chem. B 2012, 116 (28), 8222-8232. https://doi.org/10.1021/jp304893c. 


\section{Supporting information}

Reevaluating the Solution Photophysics of Tetraphenylethylene at the Origin of their Aggregation-Induced Emission Properties

Jean Rouillon*, Cyrille Monnereau* and Chantal Andraud

Univ. Lyon, ENS Lyon, CNRS, Université Lyon 1, Laboratoire de Chimie, UMR 5182, 46

Allée d'Italie, 69364 Lyon, France.

jean.rouillon@ens-lyon.fr \& cyrille.monnereau@ens-lyon.fr

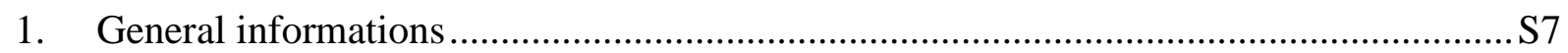

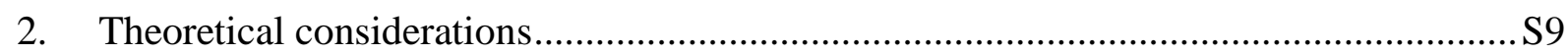

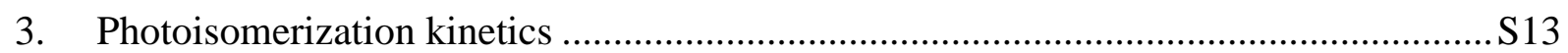

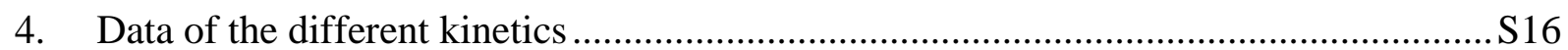

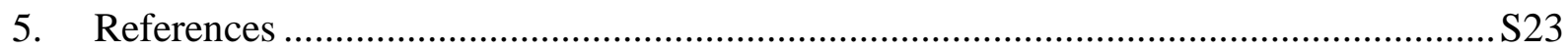




\section{General informations}

\section{NMR experiments}

${ }^{1} \mathrm{H}$ NMR spectra are recorded at room temperature on a Bruker Avance 400 spectrometer operating at $400 \mathrm{MHz}$, and ${ }^{19} \mathrm{~F}$ NMR spectra on a Bruker Avance 300 spectrometes operating at $282 \mathrm{MHz}$. $\mathrm{CDCl}_{3}$ (d, $99.8 \%$ ) were purchased from Euroisotop. Chemical shifts are reported as values (ppm) with reference to the peak of $\mathrm{CDCl}_{3}(7.26 \mathrm{ppm})$ for ${ }^{1} \mathrm{H}$ NMR and $\mathrm{C}_{6} \mathrm{~F}_{6}(-164.9 \mathrm{ppm})$ for ${ }^{19} \mathrm{~F}$ NMR.

All experiments were carried out in quartz NMR tubes, and those in degassed solvents under an inert atmosphere in quartz NMR tubes equipped with a Young's valve (Wilmad 528-LPV-7QTZ). In the latter case, solutions were degassed with five consecutive freeze-pump-thaw cycles. The accuracy of NMR integrations in the titration conditions was checked by comparison of the integrations obtained on a test sample acquired with a relaxation time $\mathrm{T} 1$ corresponding to those used in standard titration experiments, $\mathrm{T} 1$ being acquired with ca five times longer relaxation delays. Measured integrations remained unchanged.

NMR integrations and peak heights were estimated with MestReNova. Exponential fitting, tangent and exact method treatment of the obtained data were treated with Origin software.

\section{Irradiation procedures}

Irradiation source was the $450 \mathrm{~W}$ Xenon arc lamp from a Horiba Jobin-Yvon Fluorolog-3 spectrofluorimeter, irradiation wavelength was selected with a a iHR320 emission monochromator with 1200 groves.mm-1 gratings.

Irradiation experiments were carried out on a calibrated integrative sphere ( $2 \pi$ steradians covered with spectralon ${ }^{\circledR}$, model G8 from GMP.

The method of irradiation of an NMR tube in integrating sphere is fully described by Rouillon et al. ${ }^{[1]}$ The accuracy of the method was verified by comparing this set-up with conventional irradiation in a spectroscopic cuvette under constant agitation, with incident power measurement deviations of less than $3 \%$.

Briefly, Incident flow was determined by chemical actinometry based on the photoconversion of 2nitrobenzaldehyde into 2-nitrosobenzoic acid. A conversion quantum yield of 0.41 was considered in the calculations. ${ }^{[1]}$

The ratio of photons absorbed by the content of the NMR tube in the integration sphere to the incident photon flow was estimated by integrating the excitation spectra of the lamp in the absence and in the presence of the sample. 
Stock solutions in $\mathrm{CDCl}_{3}$ were prepared at specific concentrations with volumetric vessels. Solutions were transferred into the NMR tube. Irradiation was started at $\mathrm{t}=0,{ }^{1} \mathrm{H}$ or ${ }^{19} \mathrm{~F}$ NMR spectra were recorded at precise intervals of irradiation time, and the conversion was calculated on the basis of the respective integrations of reactant and product(s).

\section{Synthesis and separations of isomers}

TPE was purchased from TCI chemicals and was used without further purifications. TPE-F, TPE-OMe and S-F were synthetized according the McMurry coupling procedure described below. (E)-isomer of S-F was obtained directly pure from the synthesis. (E) and (Z) isomers of TPE-F and TPE-OMe were carefully separated by column chromatography. The resulting solutions have been protected from light to ensure stereopurity.

\section{McMurry coupling procedure}

In a dry vessel, titanium tetrachloride (3 eq.) was added to solution of zinc (6 eq.) in dry THF $(100 \mathrm{~mL})$ at $0^{\circ} \mathrm{C}$, then the mixture was refluxed for one hour. A solution of ketone of interest (1 eq.) in $20 \mathrm{~mL}$ of THF was added to the reaction mixture and refluxed overnight. The reaction was cooled with an ice-water bath and quenched by addition of saturated solution of $\mathrm{K}_{2} \mathrm{CO}_{3}$ $(100 \mathrm{~mL})$. The obtained slurry was filtered through plug of silica and rinse three times with DCM (100 mL). Organic layer was washed with brine and water, dried over $\mathrm{Na}_{2} \mathrm{SO}_{4}$, filtered and solvents were removed under vacuum. Crude product was purified by $\mathrm{SiO}_{2}$ column chromatography to give the desired olefin.

TPE-F: 4-Fluorobenzophenone (1 g, $4.99 \mathrm{mmol})$ was put in the reaction. After McMurry coupling procedure, TPE-F (0.662 g, 72\%) was obtained as a white powder. ${ }^{1} \mathrm{H}$ NMR was in accordance with the literature. ${ }^{[2]}$

(E)-isomer: ${ }^{1} \mathrm{H}$ NMR $\left(300 \mathrm{MHz}, \mathrm{CDCl}_{3}\right) \delta 7.18-7.08(\mathrm{~m}, 6 \mathrm{H}), 7.04-6.92(\mathrm{~m}, 8 \mathrm{H}), 6.78(\mathrm{t}, J=8.7 \mathrm{~Hz}$, 4H). ${ }^{19} \mathrm{~F}$ NMR (282 MHz, $\left.\mathrm{CDCl}_{3}\right) \delta-118.58$. (Z)-isomer: ${ }^{1} \mathrm{H}$ NMR $\left(300 \mathrm{MHz}, \mathrm{CDCl}_{3}\right) \delta 7.20-7.06(\mathrm{~m}$, $6 \mathrm{H}), 7.06-6.92(\mathrm{~m}, 8 \mathrm{H}), 6.81(\mathrm{t}, J=8.7 \mathrm{~Hz}, 4 \mathrm{H}) .{ }^{19} \mathrm{~F} \mathrm{NMR}\left(282 \mathrm{MHz}, \mathrm{CDCl}_{3}\right) \delta-118.46$.

TPE-OMe: 4-Methoxybenzaldehyde (1 g, $4.72 \mathrm{mmol}$ ) was put in the reaction. After McMurry coupling procedure, TPE-OMe $(0.611 \mathrm{~g}, 66 \%)$ was obtained as a white powder. ${ }^{1} \mathrm{H}$ NMR was in accordance with the literature. ${ }^{[2]}$ 
(E)-isomer: ${ }^{1} \mathrm{H}$ NMR $\left(400 \mathrm{MHz}, \mathrm{CDCl}_{3}\right) \delta 7.10(\mathrm{~m}, 6 \mathrm{H}), 7.04(\mathrm{~m}, 4 \mathrm{H}), 6.91(\mathrm{~d}, J=8.8 \mathrm{~Hz}, 4 \mathrm{H}), 6.62$ (d, $J=8.8 \mathrm{~Hz}, 4 \mathrm{H}), 3.73$ (s, 6H). (Z)-isomer: ${ }^{1} \mathrm{H}$ NMR (400 MHz, $\left.\mathrm{CDCl}_{3}\right) \delta 7.15-7.05$ (m, 6H), 7.04 -6.99 (m, 4H), 6.95 (d, $J=8.7 \mathrm{~Hz}, 4 \mathrm{H}), 6.65$ (d, $J=8.8 \mathrm{~Hz}, 4 \mathrm{H}), 3.75(\mathrm{~s}, 6 \mathrm{H})$.

S-F: 4-Fluorobenzaldehyde ( $1 \mathrm{~g}, 8.06 \mathrm{mmol})$ was put in the reaction. After McMurry coupling procedure, S-F $(0.722 \mathrm{~g}, 83 \%)$ was obtained as a white powder. ${ }^{1} \mathrm{H}$ NMR was in accordance with the literature. $^{[3]}$

${ }^{1} \mathrm{H}$ NMR $\left(300 \mathrm{MHz}, \mathrm{CDCl}_{3}\right) \delta 7.46(\mathrm{dd}, J=8.8,5.4 \mathrm{~Hz}, 4 \mathrm{H}), 7.05(\mathrm{t}, J=8.7 \mathrm{~Hz}, 4 \mathrm{H}), 6.98(\mathrm{~s}, 2 \mathrm{H}) .{ }^{19} \mathrm{~F}$ NMR $\left(282 \mathrm{MHz}, \mathrm{CDCl}_{3}\right) \delta-117.34$.

\section{Theoretical considerations}

In this section, we will consider only the $(\mathrm{Z}) \rightarrow(\mathrm{E})$ photoisomerization: the equations concerning the photoisomerization $(\mathrm{E}) \rightarrow(\mathrm{Z})$ are deduced trivially by inverting in each equation the terms relating to (E) and (Z)-isomers.

During the irradiation of a pure (Z)-isomer solution, from the first moments of the irradiation, the (E)isomer is produced and the latter also absorbs photons causing the reverse reaction to occur. Under these conditions, the determination of the quantum yield of photoisomerization must take into account this complex equilibrium, and the kinetics of the evolution of the concentration of the (Z)-isomer during its irradiation is then described according to equation $\mathrm{S} 1:^{[4]}$

$$
\frac{\mathrm{d}[\mathrm{Z}]}{\mathrm{dt}}=\Phi_{\mathrm{E} \rightarrow \mathrm{Z}} \mathrm{I}_{\mathrm{abs}} \frac{\varepsilon_{\mathrm{E}} \cdot[\mathrm{E}]}{\varepsilon_{\mathrm{Z}}[\mathrm{Z}]+\varepsilon_{\mathrm{E}}[\mathrm{E}]}-\Phi_{\mathrm{Z} \rightarrow \mathrm{E}} \mathrm{I}_{\mathrm{abs}} \frac{\varepsilon_{\mathrm{Z}} \cdot[\mathrm{Z}]}{\varepsilon_{\mathrm{Z}}[\mathrm{Z}]+\varepsilon_{\mathrm{E}}[\mathrm{E}]}
$$

With $[\mathrm{X}]$, the concentration of the $\mathrm{X}$ isomer, $\Phi_{\mathrm{x} \rightarrow \mathrm{y}}$ the quantum yield of isomerization of the (X)-isomer in $(\mathrm{Y}), \varepsilon_{\mathrm{x}}$, the molar absorption coefficient of $(\mathrm{X})$-isomer (in $\mathrm{L} \cdot \mathrm{mol}^{-1} \cdot \mathrm{cm}^{-1}$ ), $\mathrm{I}_{\mathrm{abs}}$, the absorbed photon flux (in mol. $\left.\mathrm{L}^{-1} \cdot \mathrm{s}^{-1}\right)$.

These equations can be re-expressed to afford equation $\mathrm{S} 2:^{[5]}$

$$
\frac{d[\mathrm{Z}]}{\mathrm{dt}}=\frac{\mathrm{I}_{\mathrm{abs}} \Phi_{\mathrm{E} \rightarrow \mathrm{Z} \varepsilon_{\mathrm{E}}}[\mathrm{Z}]_{0}-\mathrm{I}_{\mathrm{abs}}\left(\Phi_{\mathrm{E} \rightarrow \mathrm{Z}} \varepsilon_{\mathrm{E}}+\Phi_{\mathrm{Z} \rightarrow \mathrm{E}} \varepsilon_{\mathrm{Z}}\right)[\mathrm{Z}]}{\varepsilon_{\mathrm{E}}[\mathrm{Z}]_{0}+\left(\varepsilon_{\mathrm{Z}}-\varepsilon_{\mathrm{E}}\right)[\mathrm{Z}]}
$$

The obtained differential equation S2 is difficult to solve exactly since, on the one hand, it is non-linear and on the other hand, it still includes two unknown constants which are the two photoisomerization yields of each isomer.

A first strategy consists in obtaining the pair of solutions to the differential equation $\mathrm{S} 2$ by using regression algorithms applied to non-linear multivariate functions. Bayda et al. propose to apply the Levenberg-Marquardt algorithm to an exponential form of the solution to differential equation $\mathrm{S} 2:^{[5]}$ 


$$
\exp \left(-\frac{\mathrm{t}}{\mathrm{s}}\right)=\exp \left(\frac{\varepsilon_{\mathrm{Z}}-\varepsilon_{\mathrm{E}}}{\mathrm{I}_{\mathrm{abs}}(\mathrm{z}+\mathrm{e})} \frac{[\mathrm{Z}]-[\mathrm{Z}]_{0}}{\mathrm{~s}}\right) \times\left(1+\frac{1}{[\mathrm{Z}]_{0}}\left(1+\frac{\mathrm{e}}{\mathrm{Z}}\right)\left([\mathrm{Z}]-[\mathrm{Z}]_{0}\right)\right)^{\frac{[\mathrm{Z}]_{0} z_{\mathrm{E}}+\mathrm{e} \varepsilon_{Z}}{\mathrm{~s} \mathrm{I}_{\mathrm{abs}}(\mathrm{z}+\mathrm{e})^{2}}}
$$

With $[Z]_{0}$, the initial concentration of the (Z)-isomer, $\mathrm{z}=\varepsilon_{\mathrm{Z}} \Phi_{\mathrm{Z} \rightarrow \mathrm{E}}, \mathrm{e}=\varepsilon_{\mathrm{E}} \Phi_{\mathrm{E} \rightarrow \mathrm{Z}}$, and s, a scale factor.

By applying the fitting algorithm to the curve of $\exp \left(-\frac{\mathrm{t}}{\mathrm{s}}\right)$ versus $[\mathrm{Z}]-[\mathrm{Z}]_{0}$ (equation S4), a pair of solutions (z,e) is calculated. This method thus makes it possible to obtain the two quantum yields of photoisomerization with the study of a single kinetic and by applying it to the whole reaction.

Another strategy consists in extrapolating the kinetic constant $k_{\text {iso }}$ associated to the $(Z) \rightarrow(E)$ photoisomerization at the beginning of the reaction at $\mathrm{t}=0 .{ }^{[6]}$ At this stage, the (E)-isomer being in negligible concentration in the reaction mixture, the constant $\mathrm{k}_{\mathrm{iso}}$ can be readily obtained according to equation $\mathrm{S} 5$ :

$$
\mathrm{k}_{\text {iso }}=\lim _{\left([\mathrm{Z}]-[\mathrm{Z}]_{0}\right) \rightarrow 0} \frac{[\mathrm{Z}]_{0}-[\mathrm{Z}]}{\mathrm{t}}
$$

NMR monitoring of the evolution of concentrations of each isomer over time can be achieved by integrating the characteristic signals at the associated chemical displacements, which are displayed in table S1.

${ }^{1} \mathrm{H}$ NMR spectra of TPE, DPA, TPE-OMe, TPE-F and S-F were in accordance with the literature (vide supra). Attributions of (E/Z)-DPA-OMe and (E/Z)-DPA-F were made on the basis of their initial velocity of apparitions during the irradiation of pure corresponding (E) and (Z) isomers of TPE-OMe and TPE-F, respectively. Attributions of photocyclized product are provided for TPE-OMe (Figure 3) and TPE-F (Figure S1).

For the unsubstituted TPE, photocyclisation was followed with the integrations of the multiplets at 7.03 ppm (associated to 8 protons) and the doublet of the DPA at $8.82 \mathrm{ppm}$ (associated to 2 protons). For other studied compounds, ${ }^{1} \mathrm{H}$ NMR, singlets for the methoxy group for TPE-OMe and singlets in ${ }^{19} \mathrm{~F}$ NMR for TPE-F and S-F were considered (Table S1).

Table S1: Chemical shifts of the different peaks used in the calculation of the ratio of each isomer during irradiation experiments

${ }^{1} \mathrm{H}$ NMR chemical shift (ppm)

${ }^{19} \mathrm{~F}$ NMR chemical shift (ppm)

TPE-OMe

3.73
TPE*

7.03
TPE-F**

$\mathrm{S}-\mathrm{F}^{* * *}$
(E)-isomer 
*For convenience, the chemical shifts of the unsubstituted TPE as well as its photocyclized specie are presented here, even though, both do not have (E/Z)-isomers.

**2 photocyclized TPE-F products share the same chemical shift at $-117.10 \mathrm{ppm}$

***During the time of irradiation, no S-F photocylisation product was observed.

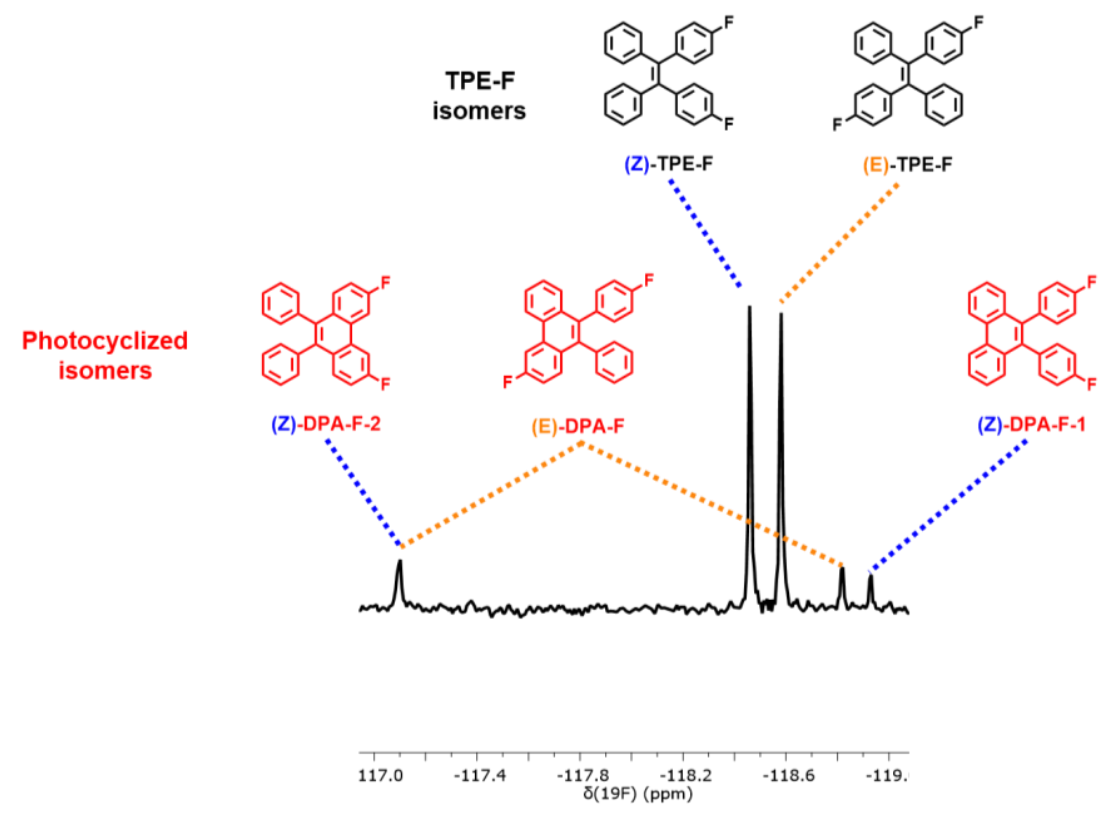

Figure S1. Close-up view ${ }^{19} \mathrm{~F}$ NMR spectrum after 3600 s irradiation of $(E)-T P E-F$ solution in $C D C l_{3}$. Assignments of TPE-F isomers and photocyclized DPA-F isomers are made.

Calculation of isomer concentrations based on the integrations or heights of each peaks were compared. Both approaches led to virtually identical evolution profiles, as illustrated by the example of irradiation of (E)-TPE-OMe (Figure S1). For the monitoring of the photoisomerization experiments, we chose to use peak heights.

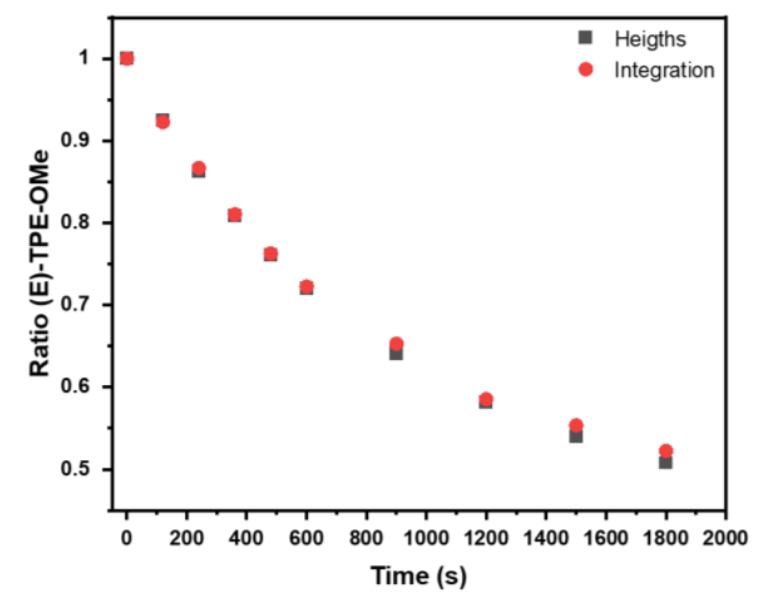


Figure S2. Comparison of ratios determined ${ }^{I} H$ NMR of (E)-TPE-OMe isomers according to different calculation methods

The ratio $\mathrm{R}(\mathrm{t})$ of $(\mathrm{Z})$-isomers of TPE derivatives over time is determined according to equation $\mathrm{S6}$ :

$$
R(t)=\frac{h_{Z}(t)}{h_{Z}(t)+h_{E}(t)}
$$

With $h_{x}(t)$, the height of the NMR peak associated with the $(X)$-isomer at the considered time.

In the un-degassed solution experiments, concomitant formation of the different cyclized products was taken into account by correcting equation S7. By doing so, the evolution of the ratio $\mathrm{R}^{\prime}(\mathrm{t})$ in (Z)-isomer over time can then be expressed as follows (equation S7):

$$
\mathrm{R}^{\prime}(\mathrm{t})=\frac{\mathrm{h}_{\mathrm{Z}}(\mathrm{t})}{\mathrm{h}_{\mathrm{Z}}(\mathrm{t})+\mathrm{h}_{\mathrm{E}}(\mathrm{t})+\sum_{\mathrm{i}} \mathrm{h}_{\mathrm{C}_{\mathrm{i}}}(\mathrm{t})}
$$

With $\sum_{\mathrm{i}} \mathrm{h}_{\mathrm{C}_{\mathrm{i}}}(\mathrm{t})$, the sum of the height of the NMR peaks associated with each photocyclized product at the considered time.

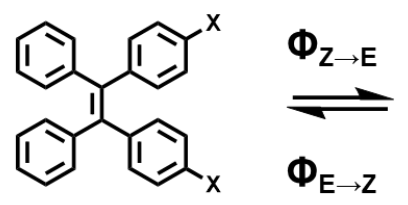

(Z)-TPE-X

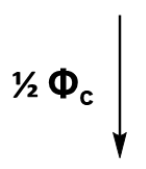<smiles>[X]c1ccc(C(c2ccccc2)c2ccccc2)cc1</smiles>

(E)-TPE-X $1 / 2 \Phi_{c}$<smiles>[Y]c1ccc(-c2c(-c3ccccc3)c3ccccc3c3cc([X])ccc23)cc1</smiles>

(E)-DPA-X

(Z)-DPA-X-1

(Z)-DPA-X-2

Figure S3. Global photochemistry of TPE-X isomers

In this calculation of the $\mathrm{R}^{\prime}(\mathrm{t})$ ratio in undegassed solvent, the decrease in the concentration of the TPE isomer is not only due to the photoconversion into its other isomer: the non-reversible formation of the DPA cyclized product also participates to the conversion kinetics (Figure S3). Thus, the kinetic constant determined for the transformation of the considered isomer is the sum of the constants associated with the photoisomerization and photocycling reactions. In order to be able to determine the yields $\Phi_{\text {iso }}$ and $\Phi_{c}$, we can therefore proceed as follows: 
(i) In a first step, the global constant $\mathrm{k}_{\mathrm{c}}$ corresponding to the photocyclization of the two isomers will be estimated by studying the evolution of the total concentration of non-cyclized TPE isomers. Assuming that the cyclisation reaction is equiprobable from each of the two isomers, we define the $\mathrm{k}_{\mathrm{c}}(\mathrm{X})$ constant from the $\mathrm{X}$ isomer $(\mathrm{X}=\mathrm{Z}$ or $\mathrm{E}$ ) (equation $\mathrm{S} 8$ ):

$$
\mathrm{k}_{\mathrm{c}}(\mathrm{X})=\frac{1}{2} \mathrm{k}_{\mathrm{c}}
$$

(ii) In a second step, the kinetics associated with TPE isomer is studied. In the example of the irradiation of the (Z)-TPE, the decrease in concentration is associated both with the formation of the (E)-isomer and the cyclisation into (Z)-DPA isomers. Taking into account this factor, the constant $\mathrm{k}_{\text {iso }}$ of the (Z)-isomer obtained by the extrapolation method at $\mathrm{t}=0$ is then defined as follows (equation S9):

$$
\mathrm{k}_{\text {iso }}^{\prime}=\mathrm{k}_{\text {iso }}+\frac{1}{2} \mathrm{k}_{\mathrm{c}}
$$

\section{Photoisomerization kinetics}

As a reminder, photoisomerization quantum yield can be derived from the measured $\mathrm{k}_{\text {iso }}$ according to equation S10:

$$
\Phi_{\text {iso }}=\frac{\mathrm{k}_{\mathrm{iso}} \cdot \mathrm{N}_{\mathrm{A}} \cdot \mathrm{V}}{\mathrm{I}_{\mathrm{abs}}}
$$

Where $\mathrm{k}_{\mathrm{iso}}$ is the kinetic constant of the considered photoinduced process (here, the isomerization) (mol. $\left.\mathrm{L}^{-1} \cdot \mathrm{s}^{-1}\right), \mathrm{N}_{\mathrm{A}}$, the Avogadro constant, $\mathrm{V}$, the volume of the solution (L), and $\mathrm{I}_{\mathrm{abs}}$, the absorbed photon flux $\left(\mathrm{s}^{-1}\right)$.

For each experiment, the volume of solution in the NMR tube was kept constant at $400 \mu \mathrm{L}$.

Therefore, the real amount $\mathrm{I}_{\mathrm{abs}}$ of photon flux absorbed by the NMR tube in the integration sphere can be calculated following equation S11:

$$
\mathrm{I}_{\mathrm{abs}}=\mathrm{I}_{0}\left(1-\frac{\mathrm{L}_{\mathrm{c}}}{\mathrm{L}_{\mathrm{a}}}\right)
$$

Where $\mathrm{I}_{0}$ corresponds to the incident photon flux as determined by chemical actinometry measurements (see above) which are displayed for both studied wavelengths in table $\mathrm{S} 2, \mathrm{~L}_{\mathrm{c}}$ and $\mathrm{L}_{\mathrm{a}}$ 
are the integrated excitation spectra of the sphere (i.e. measured signal of the light source) with and without the sample NMR tube respectively.

All photoisomerization and photocyclization quantum yield calculated accordingly are summarized in Table S3, and the kinetics, fitting curves and associated NMR spectra are presented in figures S4-S13. Data derived from these curves are summarized in Tables S4-S11.

For photoisomerisation kinetics, $\chi^{2}$ test of the exponential fit with the constant $\mathrm{k}_{\text {iso }}$ extrapolated from the tangent at zero-time are presented. For the exact method, $\chi^{2}$ test of the fit to equation S4 with the obtained photoisomerization quantum yield $\Phi_{1}$ and $\Phi_{2}$ are included in the corresponding graphs.

For photocyclisation kinetics, $\chi^{2}$ test of the linear fit with the deduced constant $\mathrm{k}_{\mathrm{c}}$ are included in the corresponding graphs. 
Table S2. Parameters of the irradiation source for photoisomerization experiments

\begin{tabular}{ccc}
\hline & TPE-F \& S-F & TPE-OMe \& TPE \\
\hline$\lambda(\mathrm{nm})$ & 308 & 320 \\
$\mathrm{I}_{0}\left(\mathrm{~s}^{-1}\right)$ & $5.40 \times 10^{14}$ & $5.29 \times 10^{14}$ \\
$\mathrm{P}(\mathrm{W})$ & $3.48 \times 10^{-4}$ & $3.28 \times 10^{-4}$ \\
\hline
\end{tabular}

Table S3. Summary of the parameters and yields of photoisomerization and photocyclization obtained during this study

\begin{tabular}{|c|c|c|c|c|c|c|c|c|c|}
\hline Compound & Condition & $\begin{array}{c}\mathrm{C}_{0} \\
\left(\mathrm{~mol} . \mathrm{L}^{-1}\right)\end{array}$ & $\begin{array}{c}\mathrm{k}_{\text {iso }} \\
\left(\mathrm{mol} \cdot \mathrm{L}^{-1} \cdot \mathrm{s}^{-1}\right)\end{array}$ & $\begin{array}{c}\mathrm{k}_{\mathrm{c}} \\
\left(\mathrm{mol} \cdot \mathrm{L}^{-1} \cdot \mathrm{s}^{-1}\right)\end{array}$ & $1-\frac{\mathrm{L}_{\mathrm{c}}}{\mathrm{I}_{\mathrm{a}}}$ & $\begin{array}{c}\Phi_{\text {iso }} \\
\text { (exact method) }\end{array}$ & $\begin{array}{c}\Phi_{\text {iso }} \\
\text { (extrapolation) }\end{array}$ & $\Phi_{\mathrm{c}}$ & Figure \\
\hline \multirow{2}{*}{ (E)-TPE-OMe } & Degassed & $2.00 \times 10^{-3}$ & $1.01 \times 10^{-6}$ & - & 0.91 & 0.50 & 0.50 & - & $2 b \& S 4 a$ \\
\hline & Undegassed & $2.00 \times 10^{-3}$ & $9.20 \times 10^{-7}$ & $1.11 \times 10^{-7}$ & 0.91 & - & 0.48 & 0.05 & S5 \& S6 \\
\hline \multirow{2}{*}{ (Z)-TPE-OMe } & Degassed & $2.00 \times 10^{-3}$ & $1.05 \times 10^{-6}$ & - & 0.91 & 0.53 & 0.53 & - & $2 a \& S 4 b$ \\
\hline & Undegassed & $2.00 \times 10^{-3}$ & $9.70 \times 10^{-7}$ & $1.12 \times 10^{-7}$ & 0.91 & - & 0.51 & 0.05 & S7 \& 4 \\
\hline (E)-TPE-F & Undegassed & $1.15 \times 10^{-3}$ & $1.01 \times 10^{-6}$ & $1.26 \times 10^{-7}$ & 0.87 & - & 0.49 & 0.07 & S8 \& S10a \\
\hline (Z)-TPE-F & Undegassed & $1.21 \times 10^{-3}$ & $1.21 \times 10^{-6}$ & $1.17 \times 10^{-7}$ & 0.93 & - & 0.51 & 0.05 & S8 \& S10b \\
\hline (E)-S-F & Undegassed & $4.55 \times 10^{-3}$ & $8.88 \times 10^{-7}$ & - & 0.84 & 0.33 & 0.39 & - & $\mathrm{S} 11 \& \mathrm{~S} 12$ \\
\hline TPE & Undegassed & $4.30 \times 10^{-3}$ & - & $9.80 \times 10^{-8}$ & 0.90 & - & - & 0.05 & $\mathrm{~S} 13$ \\
\hline
\end{tabular}


a)
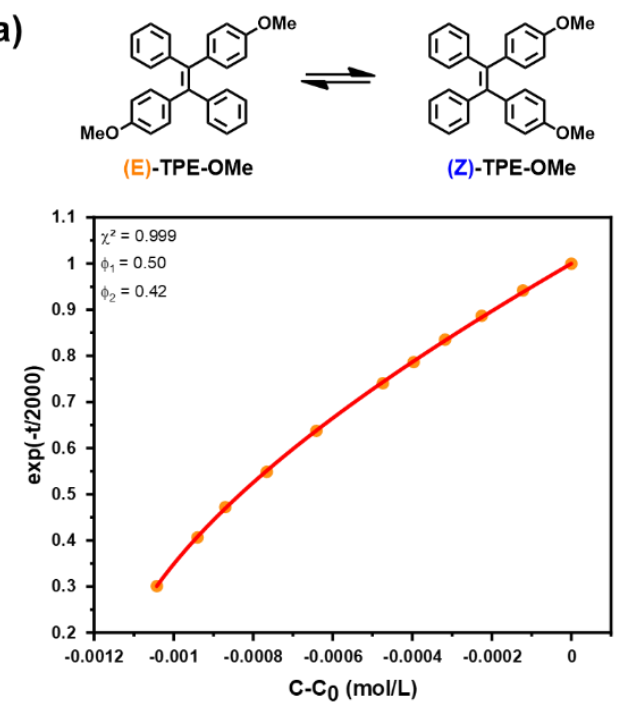

b)
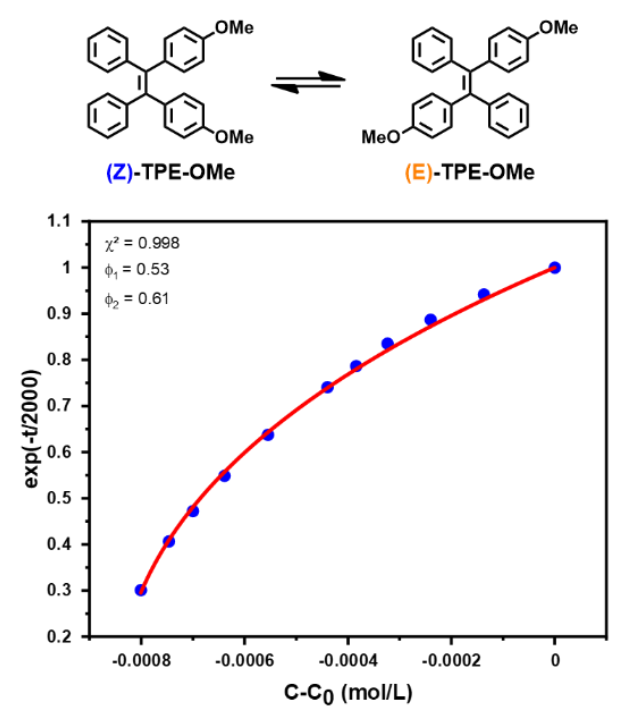

Figure S4. Exact method treatment of photoisomerization kinetics of (a) (Z)-TPE-OMe and (b) (E)-TPE$\mathrm{OMe}$ in the absence of oxygen (Red curve corresponding to the fit to equation S4)

a)

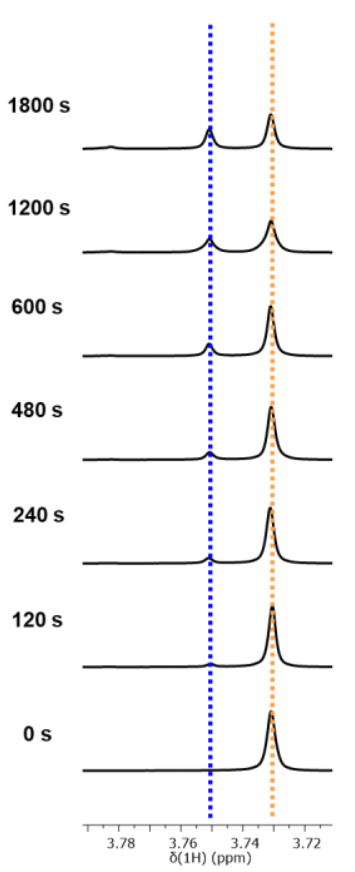

b)
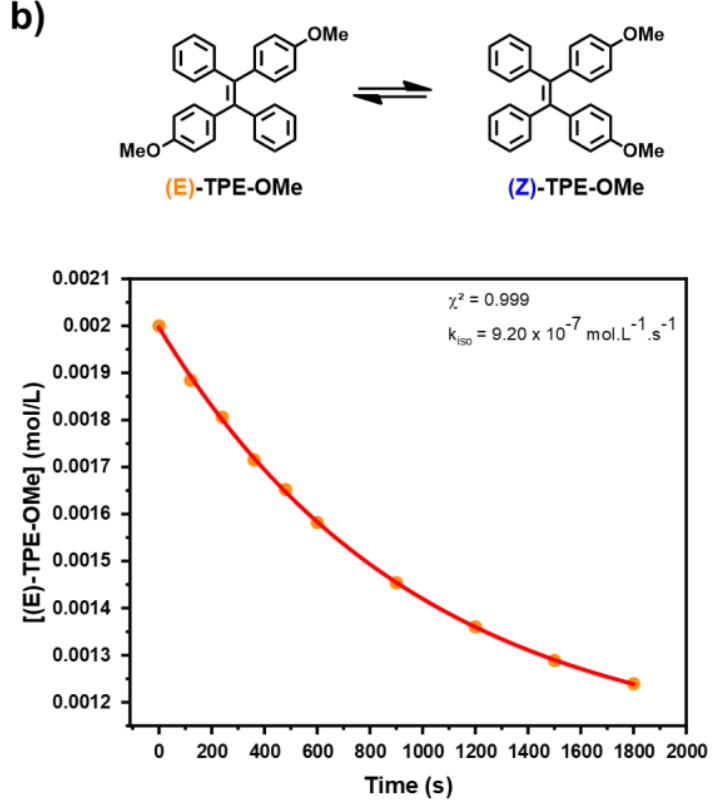

Figure S5. (a) Close-up view on methoxy region of ${ }^{1} \mathrm{H}$ NMR spectra during irradiation of (E)-TPE-OMe (in undegassed solution of $\mathrm{CDCl}_{3}$, at room temperature, with a spectrometer operating at $400 \mathrm{MHz}$ ). (b) Photoisomerization kinetic of (E)-TPE-OMe in degassed solution (Red curve corresponding to exponential fit). 


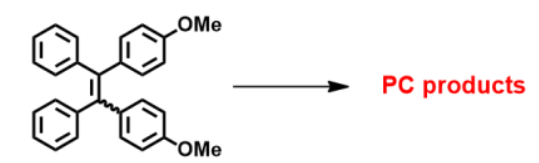

(E/Z)-TPE-OMe

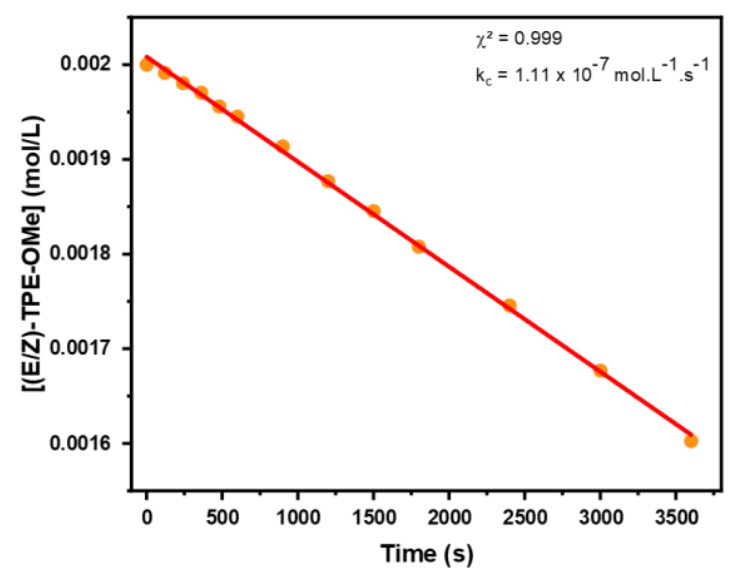

Figure S6. Photocyclization kinetic of (E)-TPE-OMe in undegassed $\mathrm{CDCl}_{3}$ solution (Red line corresponding to the linear fit).

a)

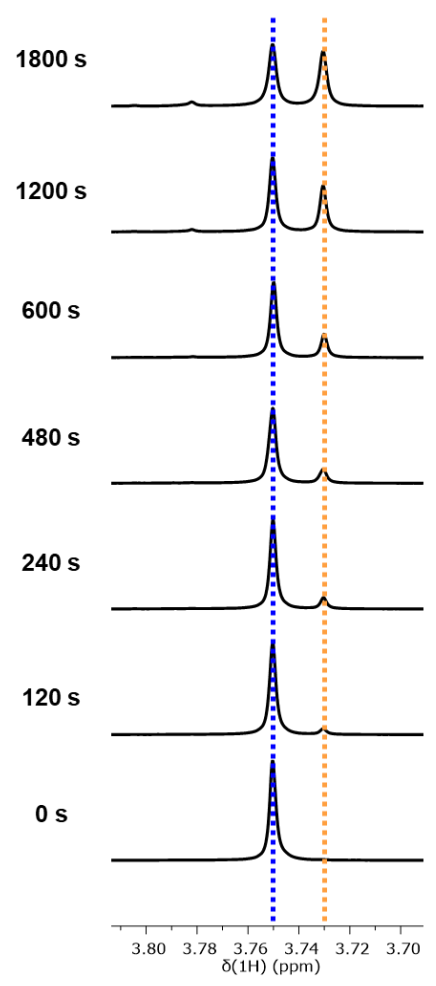

b)

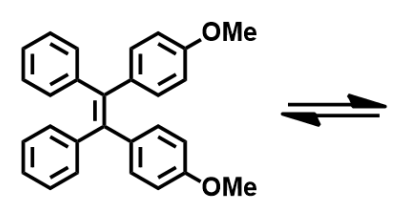

(Z)-TPE-OMe<smiles>COc1ccc(C(=C(c2ccccc2)c2ccccc2)c2ccc(OC)cc2)cc1</smiles>

(E)-TPE-OMe

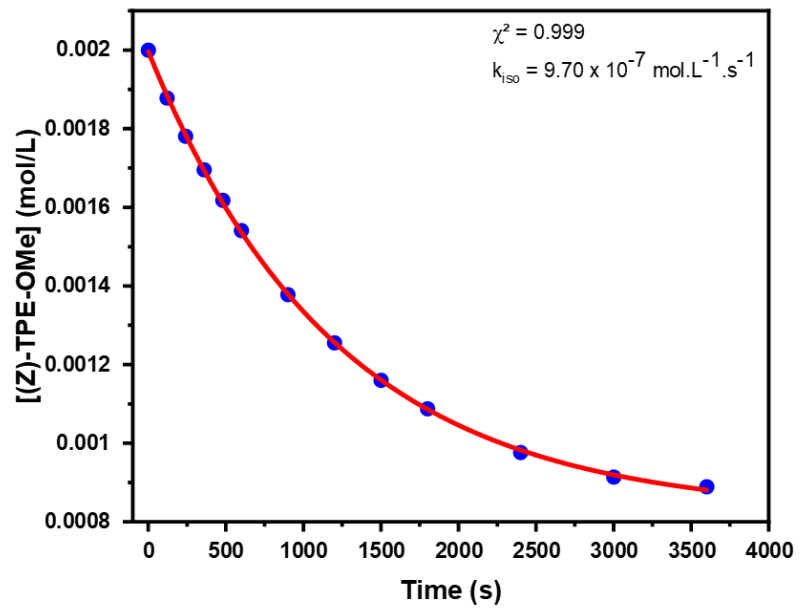

Figure S7. (a) Close-up view on methoxy region of 1H NMR spectra during irradiation of (Z)-TPE-OMe (in undegassed solution of $\mathrm{CDCl}_{3}$, at room temperature, with a spectrometer operating at $400 \mathrm{MHz}$ ). (b) Photoisomerization kinetic of (Z)-TPE-OMe in undegassed solution (Red curve corresponding to exponential fit). 
a)

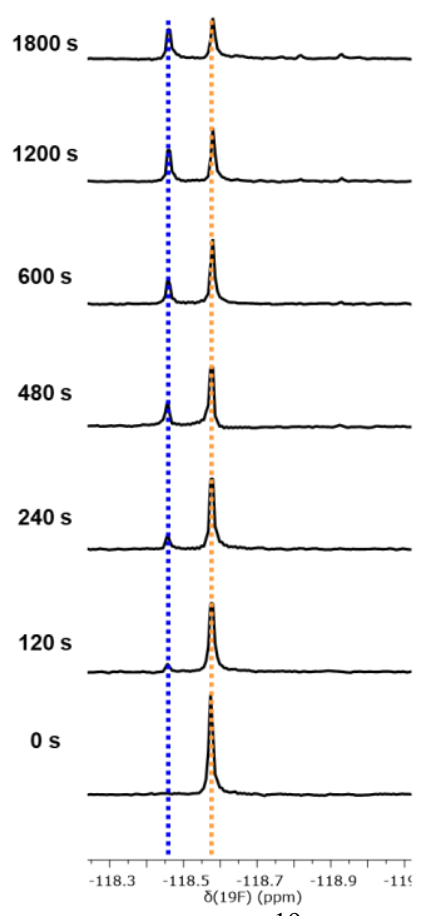

b)<smiles>Fc1ccc(C(c2ccccc2)(c2ccccc2)c2ccccc2)cc1</smiles>

(E)-TPE-F (Z)-TPE-F

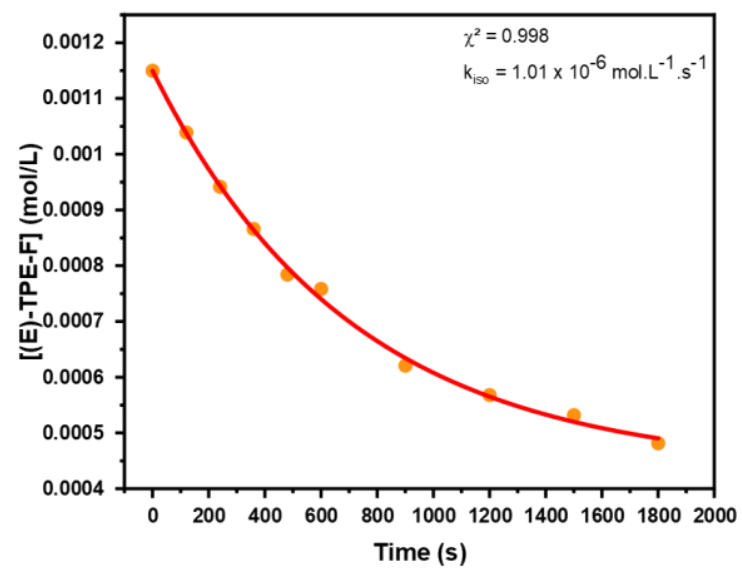

Figure S8. (a) Close-up view of ${ }^{19} \mathrm{~F}$ NMR spectra during irradiation of (E)-TPE-F (in undegassed solution of $\mathrm{CDCl}_{3}$, at room temperature, with a spectrometer operating at $282 \mathrm{MHz}$ ). (b) Photoisomerization kinetic of (E)-TPE-F in undegassed solution (Red curve corresponding to exponential fit).

a)

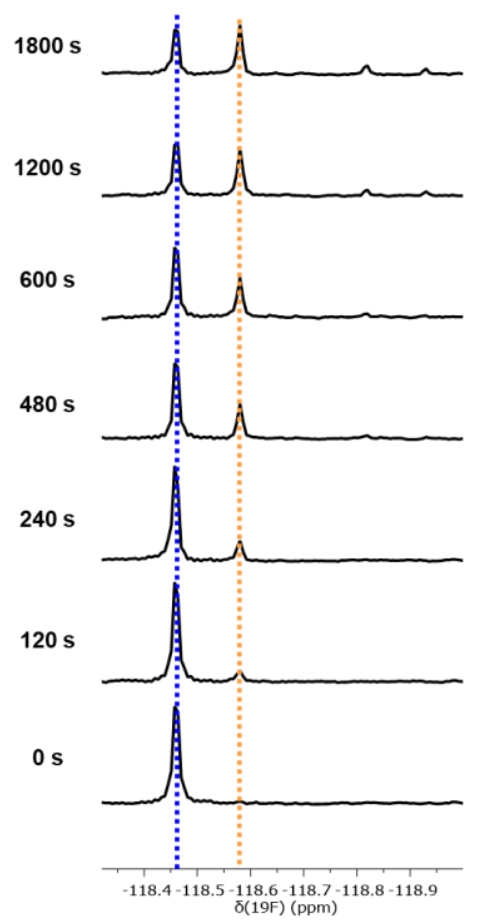

b)<smiles>Fc1ccc(C(c2ccccc2)(c2ccccc2)c2ccc(F)cc2)cc1</smiles>

(Z)-TPE-F

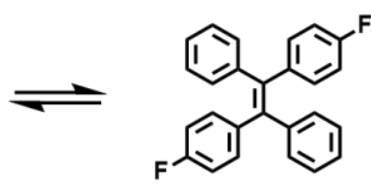

(E)-TPE-F

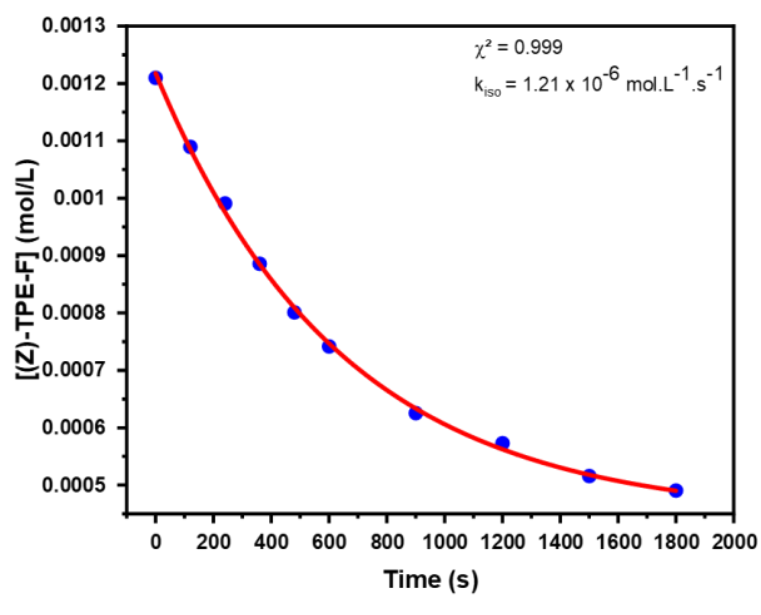

Figure S9. (a) Close-up view of ${ }^{19} \mathrm{~F}$ NMR spectra during irradiation of (Z)-TPE-F (in undegassed solution of $\mathrm{CDCl}_{3}$, at room temperature, with a spectrometer operating at $282 \mathrm{MHz}$ ). (b) Photoisomerization kinetic of (Z)-TPE-F in undegassed solution (Red curve corresponding to exponential fit). 


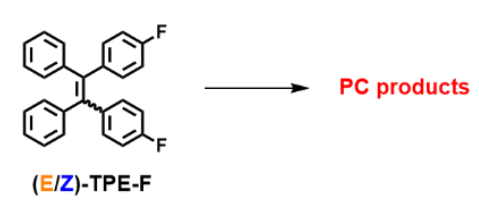

a)

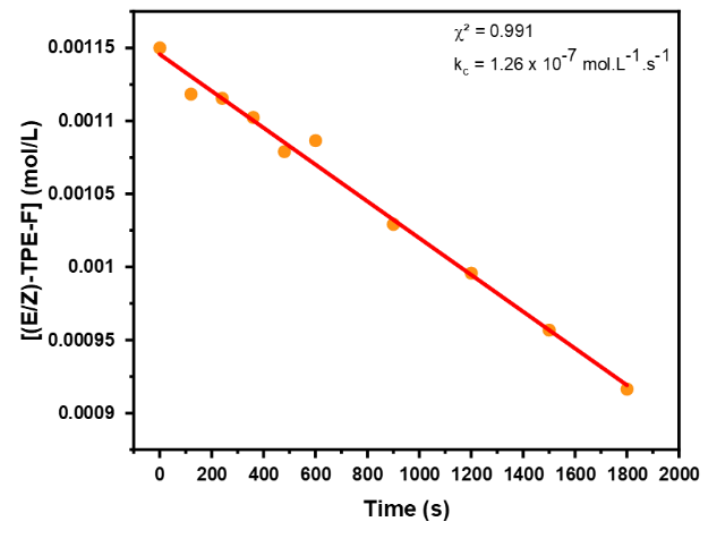

b)

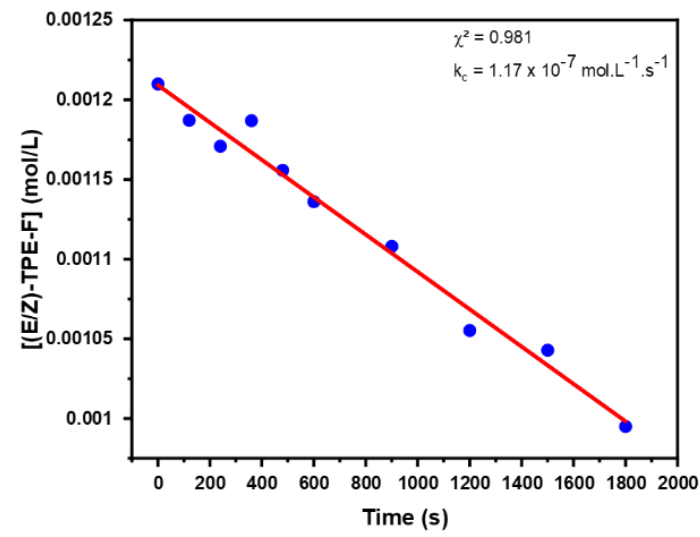

Figure S10. Photocyclization kinetics of (a) (E)-TPE-F and (b) (Z)-TPE-F in undegassed $\mathrm{CDCl}_{3}$ solution (Red line corresponding to the linear fit).

a)

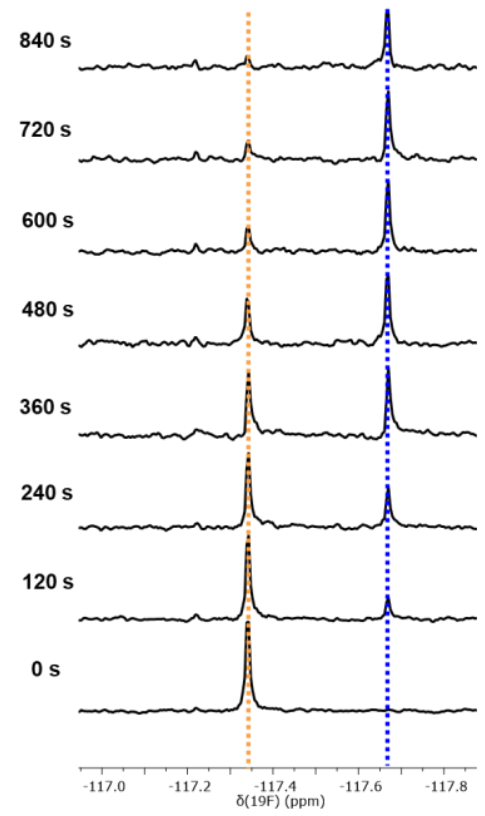

b)

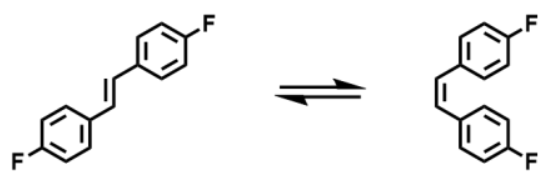

(E)-S-F

(Z)-S-F

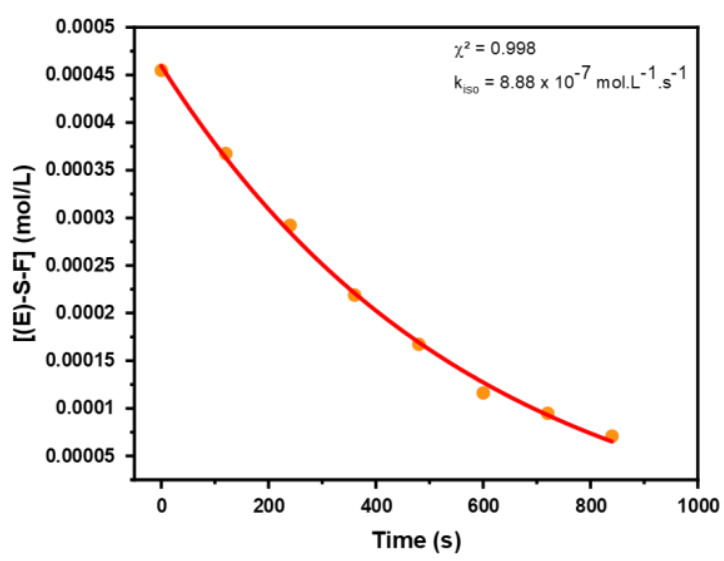

Figure S11. (a) Close-up view of ${ }^{19} \mathrm{~F}$ NMR spectra during irradiation of (E)-S-F (in undegassed solution of $\mathrm{CDCl}_{3}$, at room temperature, with a spectrometer operating at $282 \mathrm{MHz}$ ). (b) Photoisomerization kinetics of (E)-S-F in undegassed solution (Red curve corresponding to exponential fit). 


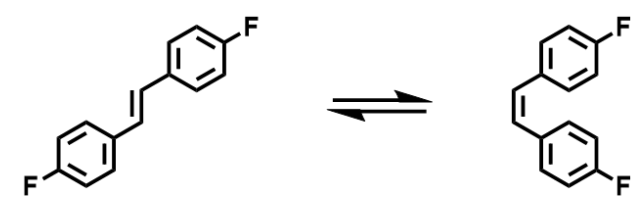

(E)-S-F (Z)-S-F

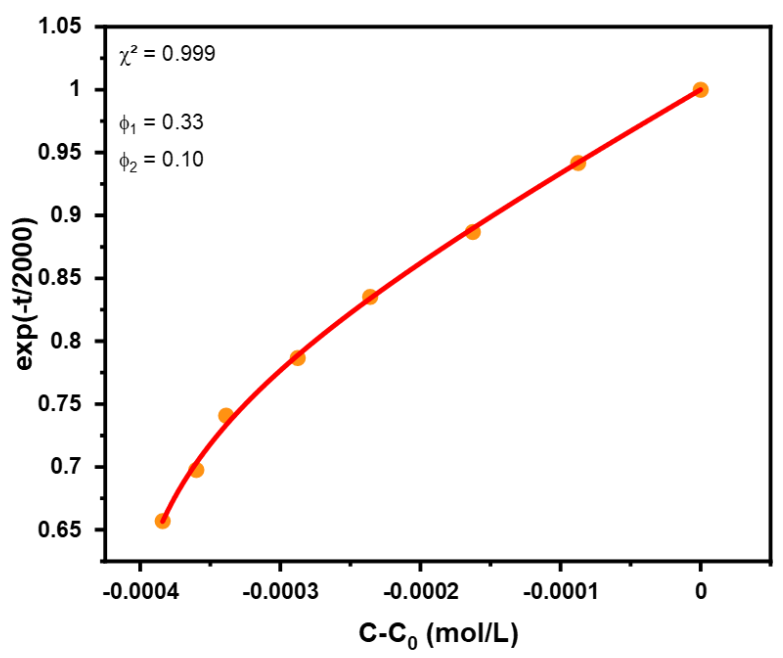

Figure S12. Exact method treatment of photoisomerization kinetics of (E)-S-F with the presence of oxygen (Red curve corresponding to the fit to equation S4)

a)

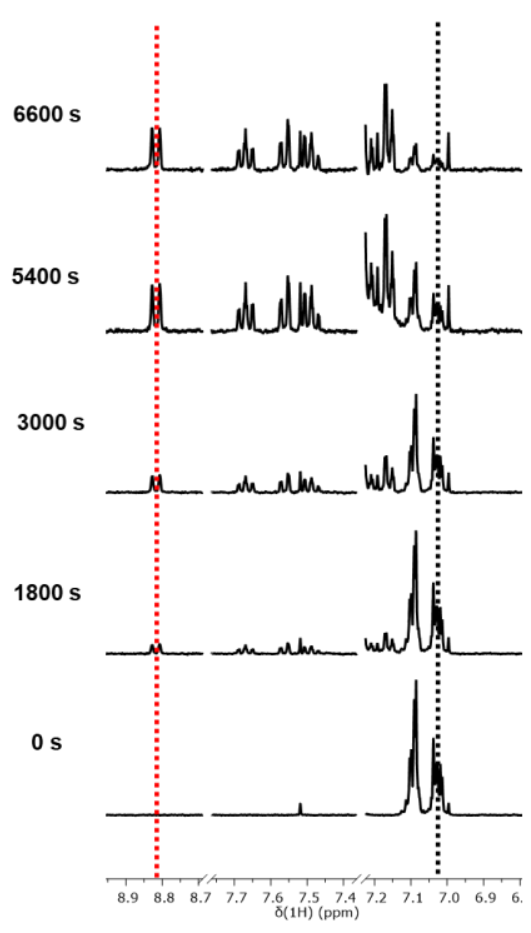

b)
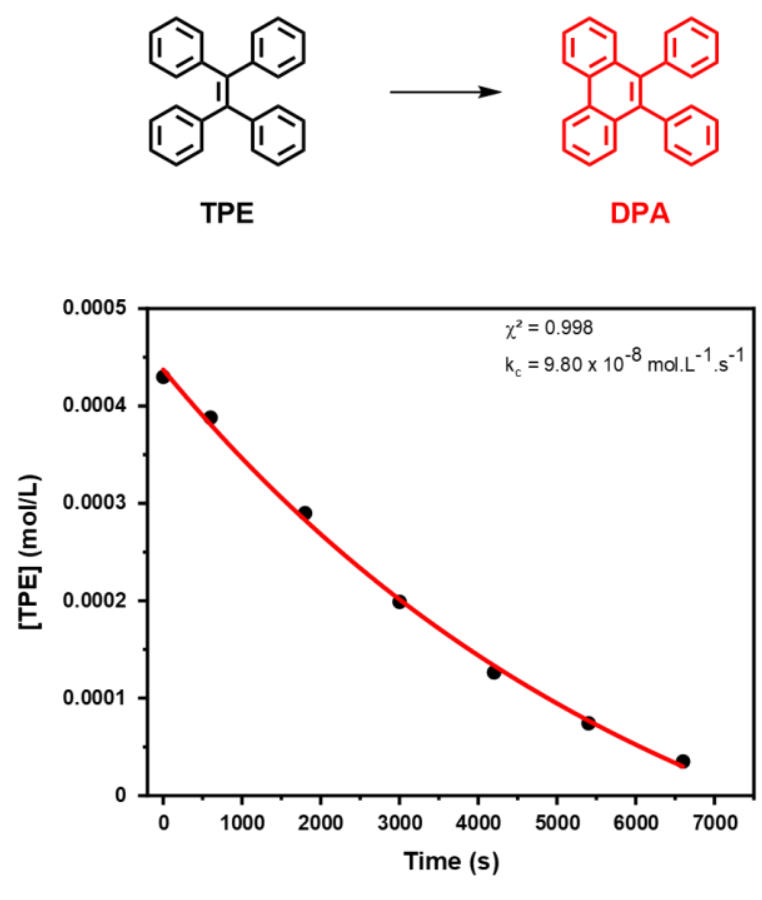

Figure S13. (a) Close-up view on aromatic region of ${ }^{1} \mathrm{H}$ NMR spectra during irradiation of TPE (in undegassed solution of $\mathrm{CDCl}_{3}$, at room temperature, with a spectrometer operating at $400 \mathrm{MHz}$ ). (b) Photocyclisation kinetics of TPE in undegassed solution (Red curve corresponding to exponential fit).

\section{Data of the different kinetics}


Table S4. Ratios of (E)-TPE-OMe calculated by $R M N-{ }^{1} H$ during irradiation (degassed solution)

Intensity (a.u.)

Time (s)

\begin{tabular}{cccc} 
& $($ Z)-Peak & $($ E)-Peak & \\
\hline 0 & - & - & 1 \\
120 & 101.2 & 1373.4 & 0.931 \\
240 & 174.3 & 1277.1 & 0.880 \\
360 & 220.4 & 1142 & 0.838 \\
480 & 256.1 & 1077 & 0.808 \\
600 & 299.4 & 1062.4 & 0.780 \\
900 & 336.7 & 877.1 & 0.723 \\
1200 & 393.5 & 838.4 & 0.681 \\
1500 & 439.7 & 816.6 & 0.650 \\
1800 & 423.1 & 710.5 & 0.627 \\
2400 & 438.9 & 657.3 & 0.600 \\
\hline
\end{tabular}

Table S5. Ratios of (Z)-TPE-OMe calculated by $R M N{ }^{-1} H$ during irradiation (degassed solution)

\begin{tabular}{|c|c|c|c|}
\hline \multirow[t]{2}{*}{ Time (s) } & \multicolumn{2}{|c|}{ Intensity (a.u.) } & \multirow[t]{2}{*}{ (Z)-isomer ratio } \\
\hline & (Z)-Peak & (E)-Peak & \\
\hline 0 & - & - & 1 \\
\hline 120 & 1529 & 99.3 & 0.939 \\
\hline 240 & 1487.3 & 189 & 0.887 \\
\hline 360 & 1252.5 & 236.6 & 0.841 \\
\hline 480 & 1333.2 & 330 & 0.801 \\
\hline 600 & 1258.4 & 391 & 0.763 \\
\hline 900 & 1099.5 & 519.2 & 0.679 \\
\hline 1200 & 932 & 578.5 & 0.617 \\
\hline 1500 & 764.7 & 589.1 & 0.565 \\
\hline 1800 & 640 & 567.9 & 0.530 \\
\hline 2400 & 503 & 547.7 & 0.479 \\
\hline 3000 & 283.2 & 328.9 & 0.463 \\
\hline 3600 & 354.4 & 439.6 & 0.446 \\
\hline
\end{tabular}

Table S6. Ratios calculated by $R M N-{ }^{1} H$ during irradiation of (E)-TPE-OMe (undegassed solution)

\begin{tabular}{|c|c|c|c|c|c|c|c|c|c|c|}
\hline \multirow[t]{2}{*}{ Time (s) } & \multicolumn{5}{|c|}{ Intensity (a.u.) } & \multirow{2}{*}{$\begin{array}{l}\text { (Z)-isomer } \\
\text { ratio }\end{array}$} & \multirow[t]{2}{*}{$\begin{array}{l}\text { (E)-isomer } \\
\text { ratio }\end{array}$} & \multirow{2}{*}{$\begin{array}{l}\text { (Z)-DPA- } \\
\text { OMe-1 ra- } \\
\text { tio }\end{array}$} & \multirow{2}{*}{$\begin{array}{l}\text { (Z)-DPA- } \\
\text { OMe-2 ra- } \\
\text { tio }\end{array}$} & \multirow[t]{2}{*}{$\begin{array}{l}\text { (E)-DPA- } \\
\text { OMe ratio }\end{array}$} \\
\hline & (Z)-Peak & (E)-Peak & $\begin{array}{c}\text { DPA-OMe- } \\
\text { Z-1 }\end{array}$ & $\begin{array}{c}\text { DPA-OMe- } \\
\text { Z-2 }\end{array}$ & $\begin{array}{c}\text { DPA-OMe- } \\
\text { E }\end{array}$ & & & & & \\
\hline 0 & - & - & - & - & - & 0.000 & 1.000 & 0.000 & 0.000 & 0.000 \\
\hline 120 & 2231.84 & 31454.89 & 23.03 & 5.53 & 232.79 & 0.066 & 0.927 & 0.001 & 0.000 & 0.007 \\
\hline 240 & 3476.16 & 30215.09 & 46.7 & 38.09 & 442.24 & 0.102 & 0.883 & 0.002 & 0.001 & 0.013 \\
\hline 360 & 5124.55 & 30032.04 & 68.87 & 120.66 & 765.62 & 0.142 & 0.832 & 0.005 & 0.003 & 0.021 \\
\hline 480 & 5786.52 & 26037.34 & 94.57 & 170.42 & 745.94 & 0.176 & 0.793 & 0.008 & 0.005 & 0.023 \\
\hline 600 & 6924.77 & 25884.79 & 177.6 & 195.11 & 1111.81 & 0.202 & 0.755 & 0.011 & 0.006 & 0.032 \\
\hline 900 & 8662.36 & 22844.29 & 288.88 & 316.03 & 1603.3 & 0.257 & 0.678 & 0.018 & 0.009 & 0.048 \\
\hline 1200 & 9757.05 & 20505.28 & 331.78 & 382.91 & 1899.04 & 0.297 & 0.624 & 0.022 & 0.012 & 0.058 \\
\hline 1500 & 10899.67 & 18304.19 & 450.1 & 498.09 & 2629.52 & 0.332 & 0.558 & 0.029 & 0.015 & 0.080 \\
\hline 1800 & 11014 & 17010.26 & 529.2 & 528.89 & 2776.53 & 0.346 & 0.534 & 0.033 & 0.017 & 0.087 \\
\hline
\end{tabular}

Table S7. Ratios calculated by $R M N-{ }^{1} H$ during irradiation of (Z)-TPE-OMe (undegassed solution) 


\begin{tabular}{|c|c|c|c|c|c|c|c|c|c|c|}
\hline \multirow[t]{2}{*}{ Time (s) } & \multicolumn{5}{|c|}{ Intensity (a.u.) } & \multirow{2}{*}{$\begin{array}{l}(\mathbf{E}) \text {-isomer } \\
\text { ratio }\end{array}$} & \multirow[t]{2}{*}{$\begin{array}{l}(\mathrm{Z}) \text {-isomer } \\
\text { ratio }\end{array}$} & \multirow{2}{*}{$\begin{array}{l}\text { (Z)-DPA- } \\
\text { OMe-1 ra- } \\
\text { tio }\end{array}$} & \multirow{2}{*}{$\begin{array}{l}\text { (Z)-DPA- } \\
\text { OMe-2 ra- } \\
\text { tio }\end{array}$} & \multirow[t]{2}{*}{$\begin{array}{l}\text { (E)-DPA- } \\
\text { OMe ratio }\end{array}$} \\
\hline & (E)-Peak & (Z)-Peak & $\begin{array}{c}\text { DPA- } \\
\text { OMe-Z-1 }\end{array}$ & $\begin{array}{c}\text { DPA- } \\
\text { OMe-Z-2 }\end{array}$ & $\begin{array}{c}\text { DPA- } \\
\text { OMe-E }\end{array}$ & & & & & \\
\hline 0 & - & - & - & - & - & 0.000 & 1.000 & 0.000 & 0.000 & 0.000 \\
\hline 120 & 99.3 & 1529 & 2.4 & 0.7 & 7 & 0.061 & 0.933 & 0.001 & 0.000 & 0.004 \\
\hline 240 & 189 & 1487.3 & 6.1 & 4.8 & 12.3 & 0.111 & 0.875 & 0.004 & 0.003 & 0.007 \\
\hline 360 & 236.6 & 1252.5 & 8.9 & 5.4 & 16 & 0.156 & 0.824 & 0.006 & 0.004 & 0.011 \\
\hline 480 & 330 & 1333.2 & 12.1 & 7.6 & 20.1 & 0.194 & 0.783 & 0.007 & 0.004 & 0.012 \\
\hline 600 & 391 & 1258.4 & 14.3 & 9.9 & 26.3 & 0.230 & 0.740 & 0.008 & 0.006 & 0.015 \\
\hline 900 & 519.2 & 1099.5 & 21.6 & 14.4 & 40.3 & 0.306 & 0.649 & 0.013 & 0.008 & 0.024 \\
\hline 1200 & 578.5 & 932 & 27.6 & 18.7 & 54.9 & 0.359 & 0.578 & 0.017 & 0.012 & 0.034 \\
\hline 1500 & 589.1 & 764.7 & 34.1 & 20.7 & 68.3 & 0.399 & 0.518 & 0.023 & 0.014 & 0.046 \\
\hline 1800 & 567.9 & 640 & 37.6 & 23.7 & 82 & 0.420 & 0.474 & 0.028 & 0.018 & 0.061 \\
\hline 2400 & 547.7 & 503 & 49.6 & 32.4 & 114.1 & 0.439 & 0.403 & 0.040 & 0.026 & 0.092 \\
\hline 3000 & 439.6 & 354.4 & 65.8 & 43.8 & 173.5 & 0.408 & 0.329 & 0.061 & 0.041 & 0.161 \\
\hline 3600 & 328.9 & 283.2 & 59.4 & 38.4 & 148.3 & 0.383 & 0.330 & 0.069 & 0.045 & 0.173 \\
\hline
\end{tabular}

Table S8. Ratios calculated by $R M N-{ }^{19} F$ during irradiation of $(E)-T P E-F$ (undegassed solution)

\begin{tabular}{|c|c|c|c|c|c|c|}
\hline Time (s) & (Z)-Peak & $\begin{array}{l}\text { Intensity (a.u.) } \\
\text { (E)-Peak }\end{array}$ & DPA-F peaks & (Z)-isomer ratio & (E)-isomer ratio & DPA-F ratio \\
\hline 0 & - & - & - & 0.000 & 1.000 & 0.000 \\
\hline 120 & 36.7 & 481.3 & 14.6 & 0.069 & 0.904 & 0.027 \\
\hline 240 & 67.5 & 366.2 & 13.4 & 0.151 & 0.819 & 0.030 \\
\hline 360 & 102 & 373.5 & 20.5 & 0.206 & 0.753 & 0.041 \\
\hline 480 & 119.2 & 317 & 28.7 & 0.256 & 0.682 & 0.062 \\
\hline 600 & 115.4 & 266.7 & 22.3 & 0.285 & 0.659 & 0.055 \\
\hline 900 & 140.8 & 214 & 41.6 & 0.355 & 0.540 & 0.105 \\
\hline 1200 & 177.2 & 235.5 & 63.9 & 0.372 & 0.494 & 0.134 \\
\hline 1500 & 171.5 & 214.9 & 78 & 0.369 & 0.463 & 0.168 \\
\hline 1800 & 150.5 & 166.9 & 80.9 & 0.378 & 0.419 & 0.203 \\
\hline
\end{tabular}

Table S9. Figure 6-19: Ratios calculated by $R M N-{ }^{19} \mathrm{~F}$ during irradiation of (Z)-TPE-F (undegassed solution)

\begin{tabular}{|c|c|c|c|c|c|c|}
\hline \multirow[t]{2}{*}{ Time (s) } & \multicolumn{3}{|c|}{ Intensity (a.u.) } & \multirow[t]{2}{*}{ (Z)-isomer ratio } & \multirow[t]{2}{*}{ (E)-isomer ratio } & \multirow[t]{2}{*}{ DPA-F ratio } \\
\hline & (Z)-Peak & (E)-Peak & DPA-F peaks & & & \\
\hline 0 & - & - & - & 1.000 & 0.000 & 0.000 \\
\hline 120 & 475.800 & 60.200 & 124.800 & 0.871 & 0.110 & 0.019 \\
\hline 240 & 418.300 & 103.200 & 252.300 & 0.776 & 0.192 & 0.032 \\
\hline 360 & 411.600 & 124.000 & 365.100 & 0.754 & 0.227 & 0.019 \\
\hline 480 & 370.100 & 156.600 & 494.400 & 0.671 & 0.284 & 0.045 \\
\hline 600 & 352.400 & 184.600 & 622.700 & 0.616 & 0.323 & 0.061 \\
\hline 900 & 306.700 & 209.900 & 926.700 & 0.544 & 0.372 & 0.084 \\
\hline 1200 & 266.600 & 216.900 & 1241.500 & 0.481 & 0.391 & 0.128 \\
\hline 1500 & 245.300 & 220.100 & 1546.900 & 0.454 & 0.408 & 0.138 \\
\hline 1800 & 224.100 & 217.900 & 1863.300 & 0.417 & 0.405 & 0.178 \\
\hline
\end{tabular}

Table S10. Ratios of (E)-S-F calculated by $R M N-{ }^{1} H$ during irradiation (undegassed solution)

\begin{tabular}{|c|c|c|c|}
\hline \multirow[t]{2}{*}{ Time (s) } & \multicolumn{2}{|c|}{ Intensity (a.u.) } & \multirow[t]{2}{*}{ (E)-isomer ratio } \\
\hline & (E)-Peak & (Z)-Peak & \\
\hline 0 & - & - & 1.000 \\
\hline 120 & 132.2 & 33.1 & 0.800 \\
\hline
\end{tabular}




\begin{tabular}{llll}
240 & 95.6 & 50.7 & 0.653 \\
360 & 67.6 & 70.4 & 0.490 \\
480 & 48.5 & 74.5 & 0.394 \\
600 & 27.6 & 75.6 & 0.267 \\
720 & 20.6 & 71.7 & 0.223 \\
840 & 12.5 & 60.6 & 0.171 \\
\hline
\end{tabular}

Table S11. Ratios of TPE calculated by $\mathrm{RMN}^{-1} \mathrm{H}$ during irradiation (undegassed solution)

\begin{tabular}{|c|c|c|c|}
\hline \multirow[t]{2}{*}{ Time (s) } & \multicolumn{2}{|c|}{ Area (a.u.) } & \multirow{2}{*}{ Ratio TPE } \\
\hline & TPE & DPA & \\
\hline 0 & - & - & 1 \\
\hline 600 & 193.93 & 7173.89 & 0.902 \\
\hline 1800 & 639.45 & 5297.06 & 0.674 \\
\hline 3000 & 966.91 & 3332.9 & 0.463 \\
\hline 4200 & 1156.52 & 1928.75 & 0.294 \\
\hline 5400 & 1167.79 & 976.16 & 0.173 \\
\hline 6600 & 1240.33 & 440.99 & 0.082 \\
\hline
\end{tabular}

\section{References}

[1] J. Rouillon, C. Arnoux, C. Monnereau, Anal. Chem. 2021, DOI 10.1021/acs.analchem.0c04540.

[2] K. Kokado, T. Machida, T. Iwasa, T. Taketsugu, K. Sada, J. Phys. Chem. C 2018, 122, $245-251$.

[3] X. Xiao, D. Lin, S. Tong, H. Luo, Y. He, H. Mo, Synlett 2011, 2011, 1731-1734.

[4] R. Gade, T. Porada, J. Photochem. Photobiol. Chem. 1997, 107, 27-34.

[5] M. Bayda, G. L. Hug, J. Lukaszewicz, M. Majchrzak, B. Marciniec, B. Marciniak, Photochem. Photobiol. Sci. 2009, 8, 16671675.

[6] J. M. Donahue, W. H. Waddell, Photochem. Photobiol. 1984, 40, 399-401. 